\title{
Children and labor market outcomes: separating the effects of the first three children
}

\author{
Simen Markussen ${ }^{1} \cdot$ Marte Strøm $^{2}$ (D)
}

Received: 23 August 2019 / Accepted: 30 September 2020 /Published online: 6 November 2020

(C) The Author(s) 2020

\begin{abstract}
We use miscarriage as a biological shock to fertility to estimate the effect of the first three children on women's and men's labor market outcomes. For women, we find that the effect is almost the same for the first, second and third child in the short run. The reduction in female earnings in the three first years after birth is on average 28 percent for the first child, 29 percent for the second child and 22 percent for the third child. The reduction is caused by drops in labor supply at the intensive margin and the extensive margin, concentrated among women in the middle part of the income distribution. There is considerable catching up after five years, but effects of the first two children persist ten years later, although they are imprecisely estimated. For men, we find evidence of increased labor supply and earnings after the first two children. We also find indications that having the first child increases take-up of health-related welfare benefits, such as disability insurance, for women, and that having a second and/or a third child increases couple stability.
\end{abstract}

Keywords Female labor supply $\cdot$ Children $\cdot$ Fertility shock $\cdot$ Health $\cdot$ Marriage

JEL Classification $\mathrm{J} 12 \cdot \mathrm{J} 13 \cdot \mathrm{J} 16 \cdot \mathrm{J} 22 \cdot \mathrm{I} 14$

\section{Introduction}

Across all OECD countries, women with children work less and have lower earnings and wages than women without children (Blau and Kahn 2013; Olivetti and Petrongolo

\footnotetext{
Responsible editor: Shuaizhang Feng

Marte Strøm

marte.strom@samfunnsforskning.no

Simen Markussen

simen.markussen@frisch.uio.no

1 Ragnar Frisch Centre for Economic Research, Oslo, Norway

2 Institute for Social Research, Oslo, Norway
} 
2016). This is also the case within individuals' career trajectories: Women work less and have lower earnings after they have children (Kleven et al. 2019a; Kleven et al. 2019 b). However, we do not fully understand the causal relationship between children and labor market outcomes, mainly because there are few sources of exogenous variation in fertility outcomes. For example, there is little evidence on the quantitative importance of having the first child compared with the second and the third. Are there economies of scale in raising children, so that the first child has the largest effect on labor supply and earnings? Alternatively, does each child induce the same demand for home time relative to time at work so that opportunity costs (foregone earnings) add up linearly with the number of children? Knowledge about the marginal effect of each child is important for families when choosing how many children to have. The sizes of the marginal effects also have implications for the design of public policies targeted at families with children.

This paper contributes to the literature estimates of the marginal effect of the first three children and thus a more comprehensive understanding of the effect of children on women's labor market outcomes. We use miscarriage as an exogenous shock to fertility to identify the effects. Furthermore, we contribute causal evidence on a broader set of labor market outcomes. In addition to labor supply and earnings, we estimate the effect of children on the take-up of sickness leave and disability insurance. Instead of attributing a decrease in employment after having children solely to a career break to care for the child, we capture whether children affect employment more severely (and potentially more long-term) through health. A mechanism behind such an effect could be that combining work and family may lead to a "double burden" (Sieber 1974) that induces or increases health problems, pushing women who are marginally employed out of the workforce. We also estimate the effect of the first three children on the husband's labor market outcomes and on couple stability.

The previous literature has exploited some sources of exogenous variation, which strongly affect the fertility margins studied. First, there is substantial evidence, based on second and third births, that the number of children has a negative impact on female labor supply. Rosenzweig and Wolpin (1980) and Angrist and Evans (1998) are the first to use twin births and the sex composition of the first two children, respectively, as exogenous variation in the probability of having an extra child. They and several later scholars using the same variation (e.g., Cruces and Galiani 2007; Hirvonen 2009; Cools and Markussen 2017) find that an additional child has a significant impact on female labor supply and earnings that seems to diminish over time. Second, infertility and in vitro fertilization (IVF) treatment have been used to estimate the effect of having the first child. Cristia (2008) and Lundborg et al. (2017) find large effects on female labor supply of having the first child in US and Danish data, respectively, while Agüero and Marks $(2008,2011)$ find no association using data from Latin American countries (Agüero and Marks 2008) and 26 developing countries (Agüero and Marks 2011). Third, there is also evidence of the importance of timing for the effects of children. Miscarriage has been used as an instrumental variable for the timing of birth, measuring the long-term effect of having children later. Hotz et al. (1997) and Hotz et al. (2005) study the effect of teenage childbearing, Miller (2009) and Miller (2011) study the effect of having children later on the children's school performance and on the career outcomes of the mother (see also Bratti 
and Cavalli 2014). Other examples of using miscarriage as instrumental variable are, e.g., Buckles and Munnich (2012) that study the effect of spacing of siblings on child school performance (identified by miscarriages before the second child) and Bratti et al. (2020) that use miscarriage as an instrument for sibship size in an analysis of migration decisions.

Recent literature on the effects of children has moved away from the use of exogenous variation in fertility to identify the effects of children in an event study framework (Kleven et al. 2019b) or a difference-in-differences framework (Angelov et al. 2016). This literature is partly a response to the need for estimates of the effect of the first child and the lack of available instruments to identify this effect (data on, e.g., IVF treatment is not easily accessible). The event study and difference-indifferences frameworks rest, however, on the assumption that the timing of children is exogenous to labor market outcomes in order for the effects to be interpreted as causal. This seems a strong assumption given the broad opportunities for couples to plan the timing of their children.

We use the random variation in the timing of births due to miscarriage to estimate the effect of children on labor market outcomes and marriage probabilities. Women who miscarry are similar to women who give birth, but their fertility is postponed: Women who miscarry do not have a child when expected and, in most cases, have a child later. Miscarriages, therefore, give rise to differences in the number of children in the short run. ${ }^{1}$ We exploit this difference between the birth group and the miscarriage group for identification. The main analysis uses an instrumental variable (IV) approach with miscarriage as an instrument for the number of children. Miscarriages occur at all birth parities, enabling us to estimate the effects of the first, second and third child. Because we use the same shock to fertility at all birth parities, we may compare marginal effects more precisely. ${ }^{2}$

The most similar analysis to ours is that by Lundborg et al. (2017), who use IVF treatment to identify the effect of having the first child on earnings, labor supply, wages, depression and divorce. They also provide comparable estimates of the second child and find that the earnings effects are larger after the firstborn than after the secondborn. The present study complements their study by exploiting a different fertility shock with a complier group representative of an average employed, pregnant woman ${ }^{3}$ and fertility margins from the first to the third child, as well as additional outcomes (sickness leave and disability insurance). In addition, our main IV specification has the "number of children" as the independent variable (similar to Angrist and Evans (1998)), which scales the effects according to the individual's number of children in each time period. Because the probability of having more children changes after the first, second and third child, accounting for new children is

\footnotetext{
${ }^{1}$ Completed fertility is not as affected in the longer run, as the miscarriage group almost catches up with the birth group over time, at least for first births.

${ }^{2}$ This is as opposed to comparing estimates of the effect of the first child with the effect of the third child using two different sources of random variation in fertility with two potentially different complier groups, for example.

${ }^{3}$ Lundborg et al. (2017) find that the fertility-treated women in their sample have higher average earnings than the average Danish woman.
} 
especially important when we compare the marginal effect of children across parities.

Our measure of miscarriage is based on register data for sickness leave. This measure has the advantage that miscarriages are not self-reported, as in the literature above, which use survey data, and therefore suffers less from potential selective misreporting. We add evidence of the suitability of viewing miscarriage as a fertility shock (conditional on age). Apart from the known increased risk of miscarriage with older age, there is almost no relationship between the probability of miscarriage and observed characteristics and labor market outcomes of the individual before the miscarriage.

We find that each of the first three children causes large short-term drops in employment and earnings. Earnings fall by 44, 19 and 20 percent in the three consecutive years after the first birth. The corresponding numbers for the second birth are 44, 29 and 15 percent, and for the third birth, 34, 23 and 10 percent. The reduction in employment at the extensive margin is larger than the reduction in employment at the intensive margin in the short run, but the opposite is true in the longer run. Although there is considerable catching up in the first few years after birth, there are still persistent effects on labor supply and earnings ten years after the birth of the first and second child. The reduction in labor supply is mainly driven by women in the middle of the earnings distribution. Having the first child also pushes some women out of the labor market and on to disability insurance. For men, we find indications that earnings and employment increase after the two first children, but the results are imprecisely estimated and most significant after the birth of the second child. It seems, therefore, that it is not only entering parenthood that shifts the division of labor in the family in a traditional direction. Instead, the division of labor shifts further after the second (and for most families, the last) child. Last, we find that having a second and third child positively affects the probability of staying married.

The paper proceeds as follows: In Section 2, we present the data and the miscarriage measure. In Section 3, we present the IV and event study models, and discuss the identifying assumptions. In Section 4, we display event study evidence of fertility and labor market changes around miscarriage and birth. In Section 5, we show the main results from the IV specification. Finally, we discuss direct effects, couple stability and additional sensitivity analyses in Section 6 before we conclude in Section 7.

\section{Data and the miscarriage measure}

The starting point of our analysis is the population of all Norwegian women who either gave birth or were registered with a sickness leave period because of miscarriage from July 2001 and through December 2004. We measure outcomes in the years 2001-2015 (pre-birth outcomes from 1996). We link data on sickness leave periods from the Norwegian Labor and Welfare Administration (NAV) with administrative data from Statistics Norway. These data provide detailed information on age, education, region of residence, links between children and parents and work status information, such as benefit take-up and labor force participation. 
We need to make a few sample restrictions. First, we include observations on only employed women. Second, we include only women of childbearing age (less than 45 years old) and age groups for whom labor market outcomes are relevant (at least 18 years old). We condition on employment because the miscarriage measure is based on data on sickness leave, available only for those employed. The exact condition is that the woman is employed in the period from four weeks before getting pregnant to four months before expected birth. ${ }^{4}$ Women in our sample therefore have the right to sickness absence from the day they become pregnant up until four months before birth (after that, losing the child will be diagnosed as a still birth and not a miscarriage).

The data we use contain start dates and end dates for all sickness absence spells certified by a physician covering the entire Norwegian population. The Norwegian sickness insurance system covers all employees, and the replacement rate during sickness leave is $100 \%$ of yearly earnings, up to a maximum of around 600,000 NOK in $2018,{ }^{5}$ and up to a maximum period of one year. As a main rule, a primary care physician (PGP) must certify all sickness leaves exceeding three days. ${ }^{6}$ The data include diagnoses forming the basis for our measure of miscarriage. ${ }^{7}$ Diagnoses can be given by the $\mathrm{PGP}^{8}$ or a healthcare specialist or hospital. ${ }^{9}$ Early miscarriages are, in most cases, registered by the PGP because they involve smaller physical reactions. ${ }^{10}$ Thus PGP-registered miscarriages may suffer from (biased) underreporting. To avoid problems of selective reporting of miscarriages, we use only diagnoses from hospitals or healthcare specialists. ${ }^{11}$ The PGP decides whether the patient should be sent to a specialist or hospital (and thus, has a hospital-registered miscarriage), not the patient herself. The decision rests on physical reactions and/or length of pregnancy (hospitals do not receive patients before they have a PGP referral in Norway). Therefore, hospital-registered miscarriages are a priori unlikely to be underreported, and the sample unlikely to be a selected sample. The average length of absence after a miscarriage is 8.6, 10.1 and 10 days for the first to the third birth, respectively.

The control group in the estimations, i.e., the sample of employed women who miscarry and have a diagnosis from a hospital or healthcare specialist, is a subsample of all women who miscarry. The treatment group, the women who give birth, include all employed women of childbearing age. The percentage of miscarriages in these

\footnotetext{
${ }^{4}$ An individual has the right to compensated sickness leave if she has worked the last four weeks.

${ }^{5}$ Around 74,000 USD, 2018 exchange rate. The maximum replacement amount is price and wage-growth adjusted each year.

${ }^{6}$ Workers employed by firms that are members of the Agreement for an Inclusive Labor Market, "IAavtalen," can have up to eight days of self-certified absence days before visiting a physician.

${ }^{7}$ The international World Health Organization (WHO) definition of a miscarriage is a pregnancy loss before the 22nd week (this includes the two weeks before pregnancy; the total length of a pregnancy is 40 weeks). The definitions might differ for different countries, and the practice may also vary between hospitals. The diagnosis codes ICD-10 used by hospitals and healthcare specialists define a miscarriage as between the 6th and the 22nd week.

${ }^{8}$ Diagnosis code ICPC-2, W82.

${ }^{9}$ Diagnosis code ICD-10, O03.

${ }^{10}$ An early miscarriage is often similar to a menstrual period.

${ }^{11}$ The diagnosis does not include abortions, which have separate codes in the diagnosis system.
} 
data (2.8 percent) is lower than what is reported in the medical literature (10-25 percent of all clinically recognized pregnancies end in miscarriage). For identification, it is crucial that the group of employed women that we observe with a miscarriage is not a selected group of women. We show in Section 3.1 that the ex ante theoretical exogeneity of hospital and healthcare specialist miscarriages is supported by empirical balance tests and pre-path analyses.

Unfortunately, for our purpose, pregnancies are not registered, only births and sickness leaves. Thus, we are unable to perfectly observe when during a pregnancy a miscarriage took place. It seems, however, plausible that miscarriages registered by hospitals or specialist healthcare services occur later in the pregnancy. We set the length of pregnancy to 17 weeks; the middle between 12 weeks (after the 12th week, most studies show that the risk of early miscarriage decreases) and 22 weeks (after the 22nd week, lost pregnancies are no longer diagnosed as miscarriages, but as stillbirths). Because hospital miscarriages usually happen after the time limit for self-decided abortions (12 weeks in Norway), the group that miscarries resembles the group that actually gives birth. The potential selectivity of the sample due to some miscarriages being "latent abortions" (Ashcraft and Lang 2006; Ashcraft et al. 2013) is less of a concern in this study. ${ }^{12}$

\section{Identification}

The aim of this paper is to estimate the causal effect of the first three children on labor market outcomes. Identifying the effect of children is complicated due to limited observed random variation in who has children and when she has them. However, there is a need for such variation, because having children is, in most cases, a planned decision depending on time-invariant and -varying individual characteristics, which correlate with labor market outcomes but are unobserved in the data (e.g., preferences over career and family, job motivation, career prospects and health).

To identify causal effects, we use the differences in fertility outcomes between women who experience a miscarriage and women who give birth: two groups pregnant with expected births in the same time period. A miscarriage, compared with a birth, leads to a postponement in the fertility outcomes in the years following the expected birth. Those who miscarry have their first, second or higher parity child in a later period (some never). We use these short-run differences in the number of children between the birth and miscarriage groups to identify the effect of the first three children on labor market outcomes.

The main model is an IV model where we use miscarriage as an instrument for the number of children. As part of the analysis, we also present the results from an event study model following a similar framework as Kleven et al. (2019b). Both

\footnotetext{
${ }^{12}$ After the 12 th week, the woman has to apply to a tribunal to have an abortion. It may be granted if the mother's health is at risk, for social reasons or if there is a risk of the child having a severe illness. A very small share, $4.2 \%$ of all abortions in 2005 , occurred after 12 weeks of pregnancy and after a decision by the tribunal (593 cases in total; Norwegian Institute of Public Health).
} 
specifications are described below. The purpose of showing the event study results is twofold. First, they provide evidence of labor market changes around birth and miscarriage, which is informative about the reduced form effects of miscarriage on labor market outcomes. ${ }^{13}$ Second, the event study estimates are useful for testing different pre-trends in labor market outcomes between those who miscarry and those who give birth, and provide indications of any direct effects of miscarriage itself.

\subsection{IV specification}

We estimate standard two-stage least squares models specified as follows:

$$
\mathrm{Y}_{i t}=\alpha+\beta \mathrm{C}_{i t}+\text { Age }_{i}+\text { Year }_{t}+X_{i}+u_{i t} .
$$

The model is estimated for each year $t$ following the expected birth (in $t=0$ ), with the first stage:

$$
\mathrm{C}_{i t}=\gamma+\delta \mathrm{z}_{i}+A g e_{i}+\text { Year }_{t}+X_{i}+v_{i t},
$$

where $Y_{i t}$ are the outcome variables of interest: number of children, earnings, employment, weekly work hours (conditional on employment), sickness leave, disability insurance and couple stability. $\mathrm{z}_{i}$ is an indicator variable for whether the pregnancy ended in miscarriage. The equations are estimated separately for each parity, $p=1-3$ using miscarriages before the first, second and third child, respectively, as the instruments.

Our main independent variable $\mathrm{C}_{i t}$ is number of children $_{i t}$. Due to large differences between birth parities in the probability of having a later child, we need to account for new children when we estimate the marginal effect of each parity child. We follow Angrist and Evans (1998) and use "number of children" as the main independent variable, reporting the labor market differences in "per child" terms.

We include a vector of age dummies $\left(A g e_{i}\right)$ that indicate age at the expected birth, measured at the monthly level. Age is the most important risk factor for miscarriage. Age also correlates with labor market outcomes. Therefore, the "age at expected birth"-dummies are the most important control variables. In addition, we control nonparametrically for business cycle variations using year dummies $\left(\right.$ Year $\left._{t}\right) . X_{i}$ contains dummies for continent of origin and industry of employment measured in $t=-2$.

We have three labor market outcomes that are unconditional on employment: yearly earnings, employment and disability insurance. In addition, we estimate the effects on weekly hours and sickness leave conditional on employment to get a measure of labor supply effects at the intensive margin and a short-term measure of health effects. Because both measures are conditional on employment, they must be interpreted with caution and in relation to the effects on employment. Yearly earnings include labor and business incomes, obtained from the tax registers. We

\footnotetext{
${ }^{13}$ The results are not exact reduced form estimates, as all period-specific coefficients are estimated simultaneously in the event study framework, while we estimate the IV model period by period after the expected birth.
} 
define employment/labor force participation as having yearly earnings above 200,000 NOK. ${ }^{14}$ Yearly earnings do not include parental leave payments. Therefore, in the analysis parental leave counts as non-employment.

The worker-employer register provides information on contracted weekly hours. As weekly hours are observed only for those who are employed, this outcome is conditional on being employed. There are some measurement errors for this variable in the registers, including missing observations. Therefore, the sample size is somewhat smaller than that for sickness leave, which is also conditional on employment. In addition, when the employee is on parental leave, the employer is not supposed to report contracted weekly hours to the register. However, practices differ between employers, and weekly hours may be measured with some error during the parental leave period, which, in turn, gives rise to measurement error in the employment effects at the intensive in the very short run $(j=0,1)$.

Table 1 shows descriptive statistics for the background variables measured in the year before pregnancy. The background characteristics of those who experience a miscarriage are very similar to those who give birth (apart from a slightly older age). Therefore, the local average treatment effect (LATE) that we estimate in Section 5 is representative of an average, employed woman who gives birth.

In Sections 3.3, 3.4 and 6.1, we discuss three conditions that must be fulfilled for these estimates to be interpreted as causal. First, the miscarriage has to affect fertility (relevance). Second, the miscarriage has to be randomly assigned (conditional on known risk factors such as age) (independence). Third, the miscarriage has to affect labor market outcomes only through fertility (exclusion). We discuss these conditions using medical literature on risk factors for miscarriage, information on background characteristics of the birth and miscarriage groups, pre-pregnancy labor market outcomes and event study estimates of fertility and labor market outcomes from four years before to ten years after the expected birth for the birth and miscarriage groups. The discussion of direct effects follows the results section as we actively use and extend the event study results for this purpose.

\subsection{Event study specification}

The estimated event study equation is as follows:

$$
\begin{aligned}
& \mathrm{Y}_{i t}=\sum_{j \neq-2} \theta_{j} \cdot \mathbf{I}[j=t] \times \mathbf{I}\left[z_{i}=0\right]+\sum_{j \neq-2} \delta_{j} \cdot \mathbf{I}[j=t] \times \mathbf{I}\left[z_{i}=1\right]+A g e_{i t} \\
& + \text { Year }_{t}+X_{i}+u_{i t} \text {. }
\end{aligned}
$$

$Y_{i t}$ are the outcome variables: number of children, earnings, employment, weekly work hours (conditional on employment), sickness leave, disability insurance and couple stability. $\mathrm{z}_{i}$ is an indicator variable for whether the pregnancy ended in miscarriage. $\sum_{j \neq-2} \mathbf{I}[j=t]$ is the full set of event time dummies from four years before

\footnotetext{
${ }^{14}$ It is not clear how to define employment, i.e., how much one should work to be defined as employed. In Fig. 4, this assumption is relaxed, and the effects on seven different cutoffs are displayed.
} 
Table 1 Balance test: Descriptive statistics of birth and miscarriage groups in $t=-2$

\begin{tabular}{|c|c|c|c|c|c|c|c|c|c|}
\hline & \multicolumn{3}{|c|}{ First child } & \multicolumn{3}{|c|}{ Second child } & \multicolumn{3}{|c|}{ Third child } \\
\hline & Birth & Misc. & $p$ value & Birth & Misc. & $p$ value & Birth & Misc. & $p$ value \\
\hline \multicolumn{10}{|l|}{ Observations } \\
\hline Observations in data & 82.679 & 1.824 & & 36.036 & 764 & & 18.792 & 481 & \\
\hline Employed and age 18-45 & 46.681 & 1.269 & & 21.198 & 589 & & 10.295 & 359 & \\
\hline \multicolumn{10}{|l|}{ Individual characteristics } \\
\hline Age & 27.21 & 28.02 & 0.00 & 29.88 & 31.62 & 0.00 & 32.03 & 33.85 & 0.00 \\
\hline Years of education & 14.83 & 14.82 & 0.87 & 14.51 & 14.68 & 0.21 & 14.42 & 14.42 & 0.99 \\
\hline \multicolumn{10}{|l|}{ Industry } \\
\hline Agricult., forestry, fishing & 0.01 & 0.01 & 0.62 & 0.01 & 0.01 & 0.87 & 0.01 & 0.01 & 0.94 \\
\hline Manufacturing & 0.08 & 0.07 & 0.33 & 0.09 & 0.08 & 0.42 & 0.08 & 0.09 & 0.85 \\
\hline Retail trade/tourism & 0.15 & 0.17 & 0.10 & 0.15 & 0.13 & 0.34 & 0.12 & 0.13 & 0.60 \\
\hline Adm., private sector & 0.15 & 0.16 & 0.66 & 0.14 & 0.16 & 0.19 & 0.12 & 0.15 & 0.14 \\
\hline Public administration & 0.06 & 0.07 & 0.46 & 0.07 & 0.08 & 0.14 & 0.07 & 0.04 & 0.03 \\
\hline Education & 0.12 & 0.10 & 0.03 & 0.12 & 0.11 & 0.24 & 0.14 & 0.11 & 0.11 \\
\hline Health services & 0.33 & 0.33 & 0.94 & 0.34 & 0.33 & 0.70 & 0.38 & 0.38 & 0.97 \\
\hline \multicolumn{10}{|l|}{ Continent of origin } \\
\hline Europe & 0.09 & 0.08 & 0.61 & 0.08 & 0.10 & 0.05 & 0.06 & 0.11 & 0.00 \\
\hline Africa & 0.01 & 0.01 & 0.19 & 0.01 & 0.01 & 0.58 & 0.01 & 0.01 & 0.52 \\
\hline Asia & 0.03 & 0.03 & 0.20 & 0.03 & 0.04 & 0.12 & 0.03 & 0.04 & 0.08 \\
\hline America & 0.01 & 0.00 & 0.07 & 0.00 & 0.01 & 0.03 & 0.00 & 0.01 & 0.19 \\
\hline \multicolumn{10}{|l|}{ Labor market outcomes } \\
\hline Labor earnings, NOK & 472,045 & 478,618 & 0.67 & 402,706 & 431,447 & 0.00 & 401,305 & 419,784 & 0.09 \\
\hline Employment & 0.88 & 0.87 & 0.74 & 0.87 & 0.88 & 0.41 & 0.88 & 0.89 & 0.55 \\
\hline Weekly hours (cond.) & 34.48 & 34.42 & 0.81 & 33.04 & 33.94 & 0.02 & 30.75 & 30.98 & 0.68 \\
\hline Sickness leave & 0.03 & 0.03 & 0.42 & 0.05 & 0.05 & 0.39 & 0.05 & 0.05 & 0.70 \\
\hline Disability insurance & 0.01 & 0.01 & 0.73 & 0.01 & 0.01 & 0.12 & 0.01 & 0.01 & 0.83 \\
\hline
\end{tabular}

For each child, the first two columns report the mean values of the background characteristics and outcome variables measured in the year before the expected birth. Industry codes are grouped into six categories. The third column reports $p$ values from a $t$-test of whether the means are statistically significantly different

the expected birth to ten years after $(j=-4$ to $j=10)$. $\sum_{j \neq-2} \theta_{j}$ are the estimated coefficients on each event period for the group that gives birth, and $\sum_{j \neq-2} \delta_{j}$ for the group that miscarries. $j=0$ is the time of the expected birth. We use event time $j=-2$ as the reference time period, which means that all coefficients are estimated relative to the year before pregnancy. We include vectors for age dummies $\left(A g e_{i t}\right)$ and year dummies $\left(\right.$ Year $\left._{t}\right)$ to control non-parametrically for life cycle and business 

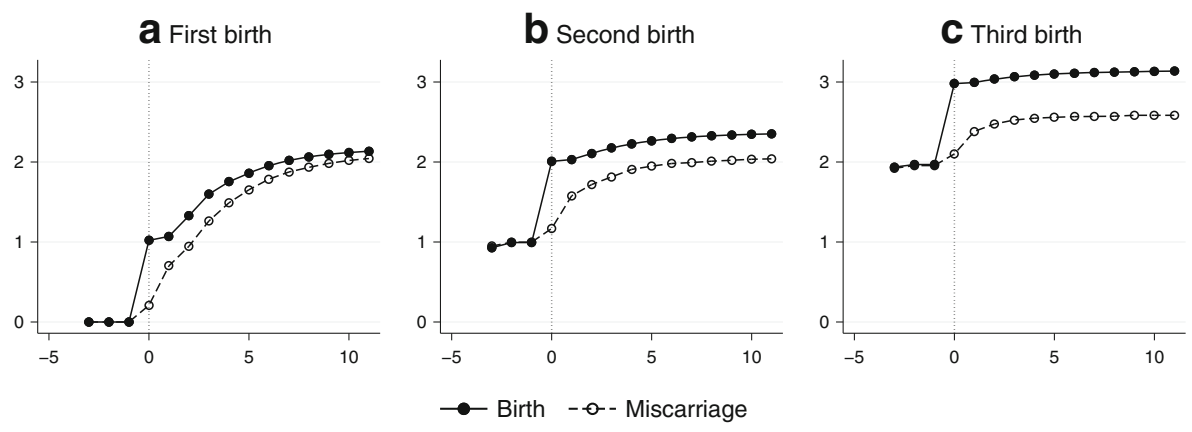

Fig. 1 The average number of children in the birth and miscarriage group (treatment and control group). $t=0$ is year of expected birth

cycle variations in labor market outcomes. $X_{i}$ contains dummies for continent of origin and industry of employment measured in $t=-2$. The equations are estimated separately for each parity, $p=1-3$, as in the IV setup.

\subsection{How miscarriage affects fertility (relevance)}

Figure 1 shows the average number of children in the birth group and the miscarriage group. There are small and/or statistically insignificant differences in the number of children in the years preceding pregnancy. After a miscarriage or birth, there is a statistically significant difference in the number of children, implying that miscarriages are highly relevant as fertility shocks.

The first stage coefficients from the IV specification are reported in Fig. 7 in the Appendix and are strong in all periods. The differences are largest the year of the expected birth $(t=0)$. In the following years, the miscarriage group partly catches up. The catching-up effect is strongest after a miscarriage preceding the first birth. After five years, the difference in the number of children is around 0.2 between the birth and miscarriage groups. After ten years, it is less than 0.1. A miscarriage before the second or third child has more long-term effects on fertility ten years after the expected birth. The difference in the number of children is still 0.5 five years after a miscarriage before the third child. For each parity, the number of children also continues to grow for the birth group. An independent variable indicating the "number of children" at each time $t$ therefore better captures the differences in fertility outcomes than the "have child" indicator.

\subsection{Miscarriage as a random shock to fertility (independence)}

According to the medical literature, in most cases miscarriages are caused by anomalies in the fetus (e.g., chromosomal aberrations) or a physical defect in the mother (uterine anatomic defect) (Kline et al. 1989; Garcia-Enguidanos et al. 2002). In addition, the risk of miscarriage increases with age, particularly in the late thirties 
(Magnus et al. 2019). The impact of behavioral factors on the miscarriage risk is small; extreme behavior, such as high alcohol consumption or drug use, can lead to miscarriage, although rarely. Other risk factors may be workplace toxicants (see Garcia-Enguidanos et al. 2002 for a review).

We test the exogeneity of miscarriage to pre-pregnancy labor market outcomes in four ways. First, we include a balancing test of the differences in the observed characteristics and pre-pregnancy labor market outcomes in $t=-2$ between women who miscarry and women who give birth (see Table 1). The table shows that women who miscarry are, on average, one to two years older than the women who give birth. The table also shows that there are some statistically significant differences in industry of employment and continent of origin, but these differences are small and inconsistent across birth parities. In the estimations, we control for age at the expected birth, thus controlling for increased risk at older ages. We also control for continent of origin, industry and calendar time, eliminating risk factors related to these characteristics. Women who miscarry have somewhat higher pre-pregnancy earnings, but this is, as we show in the next paragraph, not a statistically significant predictor of miscarriage once we control for age. Overall, the women who miscarry have similar observable characteristics as the women who give birth. Therefore, the LATE that we estimate in Section 5 is representative of an average, employed woman who gives birth.

The second test of exogeneity is a regression of pre-pregnancy labor market outcomes on the probability of miscarriage (Table 2). We include different sets of control variables in columns 1-3 to see how sensitive the results are to the different controls. In the first column, we include only calendar time. There is a statistically significant relationship between miscarriage and pre-pregnancy labor market outcomes in this sparse model. Moving to the second column, we add age at the expected birth and the statistically significant relationship with pre-birth labor market outcomes disappears. Adding controls for industry and continent of origin has negligent impact on this result. We conclude from this test that miscarriage is exogenous to pre-pregnancy labor market outcomes - conditional on age at the expected birth.

Notably, miscarriage is not statistically significantly related to any of the healthrelated outcomes, i.e., sickness leave or disability insurance in $j=-2$ in Table 2. This is reassuring, as we may be concerned that miscarriage relates to the woman's general health condition. This concern might be especially large for women who experience repeated miscarriages. Although this group is small, ${ }^{15}$ a potential selection on health may bias the results downward. An additional source of bias related to repeated miscarriages is that we do not measure the planned timing of children well for the group experiencing repeated miscarriages. If the miscarriage we observe is not their first, we may compare those who have children with a group who planned to have children earlier. The third test of independence, is to estimate the model excluding the group with more than one miscarriage from the sample (see Section 6.3). The results are unchanged when we exclude these women from the sample.

\footnotetext{
${ }^{15}$ Only 8.5 percent in the data are observed with several miscarriages if we use sickness leave prescribed by the PGP, hospitals and the healthcare specialist
} 
Table 2 OLS regression of background characteristics and pre-pregnancy labor market outcomes on the probability of miscarriage

\begin{tabular}{|c|c|c|c|c|c|c|}
\hline & All births & & & 1st birth & 2nd birth & 3rd birth \\
\hline \multirow[t]{2}{*}{ Labor earnings } & $0.001 * * *$ & -0.000 & -0.000 & -0.000 & -0.000 & -0.001 \\
\hline & $(0.000)$ & $(0.000)$ & $(0.000)$ & $(0.000)$ & $(0.001)$ & $(0.001)$ \\
\hline \multirow[t]{2}{*}{ Employment } & $-0.004^{*}$ & -0.001 & -0.001 & 0.000 & -0.006 & 0.003 \\
\hline & $(0.002)$ & $(0.002)$ & $(0.002)$ & $(0.003)$ & $(0.004)$ & $(0.007)$ \\
\hline \multirow[t]{2}{*}{ Hours, conditional } & -0.000 & -0.000 & 0.000 & -0.000 & 0.0001 & -0.000 \\
\hline & $(0.000)$ & $(0.000)$ & $(0.000)$ & $(0.000)$ & $(0.0001)$ & $(0.000)$ \\
\hline \multirow[t]{2}{*}{ Sickness leave } & -0.001 & -0.004 & -0.005 & -0.011 & 0.007 & -0.011 \\
\hline & $(0.005)$ & $(0.005)$ & $(0.005)$ & $(0.008)$ & $(0.010)$ & $(0.014)$ \\
\hline \multirow[t]{2}{*}{ Disability } & -0.005 & -0.011 & -0.010 & -0.008 & -0.020 & -0.002 \\
\hline & $(0.007)$ & $(0.007)$ & $(0.007)$ & $(0.009)$ & $(0.012)$ & $(0.019)$ \\
\hline \multicolumn{7}{|l|}{ Controls } \\
\hline Calendar time & Yes & Yes & Yes & Yes & Yes & Yes \\
\hline Age & No & Yes & Yes & Yes & Yes & Yes \\
\hline All background characteristics & No & No & Yes & Yes & Yes & Yes \\
\hline \multicolumn{7}{|l|}{$F$-test } \\
\hline$F$ & 3.155 & 1.022 & 0.878 & 1.010 & 1.256 & 0.482 \\
\hline$P$ & 0.008 & 0.403 & 0.495 & 0.410 & 0.280 & 0.790 \\
\hline Observations & 80,266 & 80,266 & 80,266 & 47,825 & 21,787 & 10,654 \\
\hline
\end{tabular}

Ordinary least squares (OLS) regression of the background characteristics and pre-pregnancy labor market outcomes measured in the year before the expected birth on the probability of miscarriage. Each column reports the coefficients and $F$-statistics from a regression of the explanatory variables indicated in the left column on miscarriage, in the sample indicated in the column header. Significance indicated by asterisks: $* * * p<1$ percent, $* * p<5$ percent and $* p<10$ percent

Fourth, the event study estimates in Figs. 2 and 3 show that after controlling for observable characteristics, the birth and miscarriage groups are on similar pre-pregnancy labor market/welfare paths. This result lends further support to the exogeneity of miscarriage in labor market and health outcomes.

\section{Results for the event study model}

Figures 2 and 3 show how labor market outcomes of the birth and miscarriage groups are similar before the expected birth and diverge markedly afterward. After the expected birth, the women who give birth have consistently lower earnings and lower labor supply than those who miscarry. For women who experience a miscarriage, earnings and labor supply decrease later (when they also have children). A miscarriage gives rise, therefore, to statistically significant differences in fertility outcomes and labor market outcomes. 

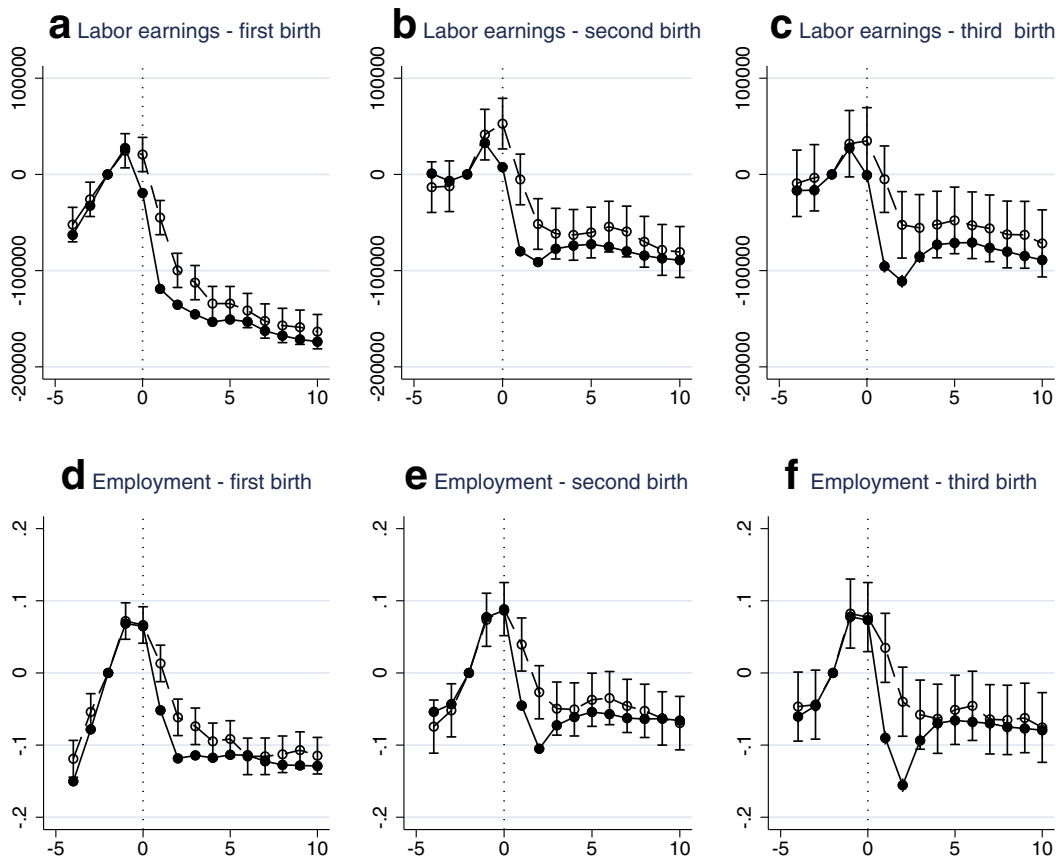

9 Work hours - first birth

h Work hours - second birth

h Work hours - third birth
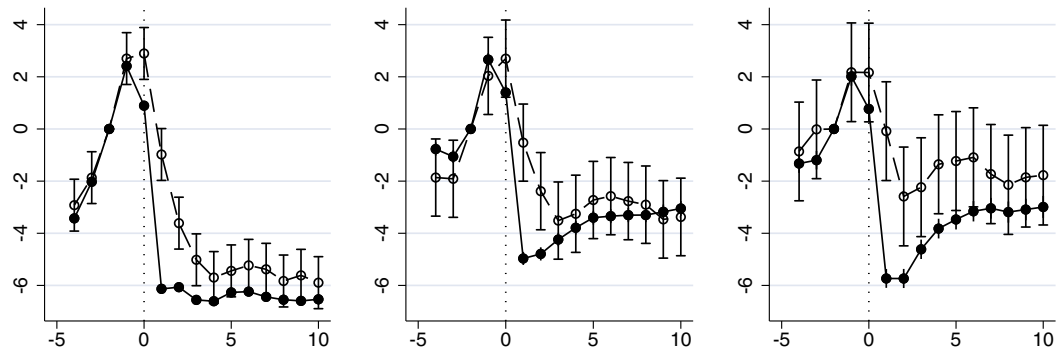

\section{Birth $\quad-0--$ Miscarriage}

Fig. 2 Event study graphs showing labor market outcomes before and after the expected birth, birth and miscarriage groups separately. Event time $=0$ is the year of the expected birth. Equations are estimated separately for each parity $p=1-3$. Included covariates are indicator variables for age at the expected birth measured in months and calendar year, continent of origin and industry in $t=-2$. Error bars show $95 \%$ confidence intervals

The event study estimates for the birth group are comparable to those by Kleven et al. (2019b): Giving birth causes sharp drops in labor supply and earnings. There is a larger drop after the first child, but this may, in part, be due to drops after the birth 

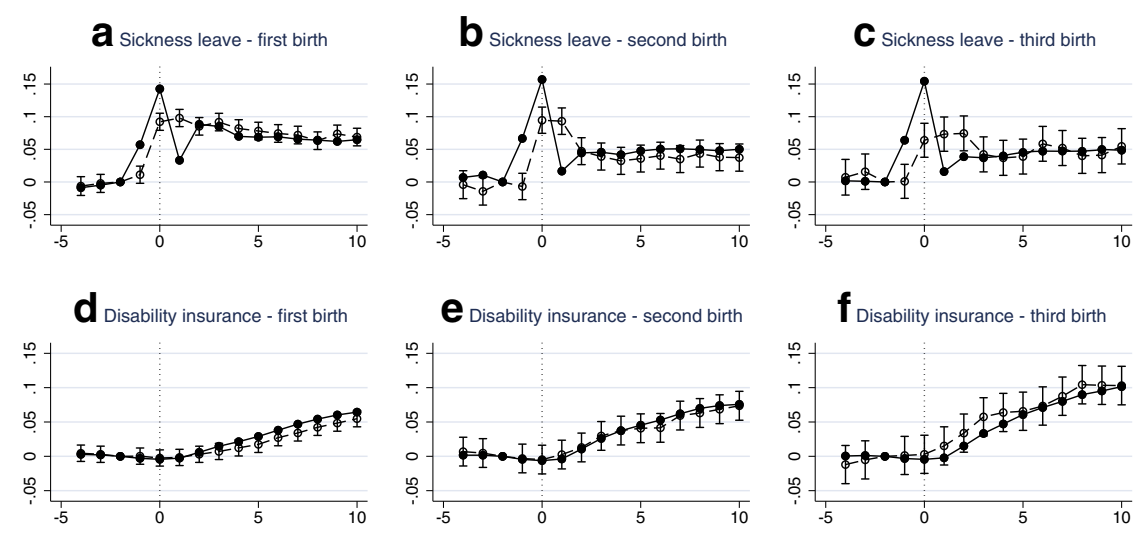

$$
\longrightarrow \text { Birth --๑-- Miscarriage }
$$

Fig. 3 Event study graphs showing labor market outcomes before and after expected birth, birth and miscarriage group separately. Event time $=0$ is the year of the expected birth. Equations are estimated separately for each parity $p=1-3$. Included covariates are indicator variables for age at the expected birth measured in months and calendar year, continent of origin and industry in $t=-2$. Error bars show $95 \%$ confidence intervals

of higher parity children. To get a precise estimate of the marginal effects of the first, second and third child, we need to adjust for later births, which is what we do in the IV specification.

A causal interpretation of the event study estimates requires that the timing of children is exogenous to labor market outcomes (see Kleven et al. 2019b). Theoretically, this seems to be a strong assumption, because having children is usually a planned decision, depending on time-invariant and time-varying unobserved individual characteristics, correlated with labor market outcomes. In the event study estimates, we see, for example, that labor market participation rates before birth are increasing. This suggests that many women in Norway start working before they have their first child. The timing of children is, in that case, not exogenous to the timing of labor market entrance, which, in turn, depends on, e.g., educational length. This gives rise to potential bias in the estimated event study coefficients and emphasizes the need for exogenous variation in fertility outcomes.

\section{Results for the IV model}

\subsection{Mothers' labor market outcomes}

Table 3 reports the results for the IV estimations. We report all coefficients in Fig. 8 in the Appendix, but include only the coefficients from $t=1$ to $t=5$ here to make the table more readable. We find large earnings and labor supply effects in the first years 
Table 3 IV estimates of the effect of the number of children on labor market outcomes, mothers

\begin{tabular}{|c|c|c|c|c|c|c|}
\hline & \multirow{2}{*}{$\begin{array}{l}\text { Mean } \\
t=-2\end{array}$} & \multicolumn{5}{|c|}{ Second stage, 2SLS } \\
\hline & & $t=1$ & $t=2$ & $t=3$ & $t=4$ & $t=5$ \\
\hline \multicolumn{7}{|l|}{ First child } \\
\hline Labor earnings & 461,344 & $\begin{array}{l}-204,291 * * * \\
(14,512)\end{array}$ & $\begin{array}{l}-87,945^{* * *} \\
(16,927)\end{array}$ & $\begin{array}{l}-92,576^{* * * *} \\
(20,352)\end{array}$ & $\begin{array}{l}-55,158^{*} \\
(29,710)\end{array}$ & $\begin{array}{l}-68,102 * \\
(38,647)\end{array}$ \\
\hline Employment & 0.875 & $\begin{array}{l}-0.177 * * * \\
(0.024)\end{array}$ & $\begin{array}{l}-0.142 * * * \\
(0.029)\end{array}$ & $\begin{array}{l}-0.117 * * * \\
(0.032)\end{array}$ & $\begin{array}{l}-0.057 \\
(0.040)\end{array}$ & $\begin{array}{l}-0.096^{*} \\
(0.051)\end{array}$ \\
\hline Weekly hours & 34.497 & $\begin{array}{l}-3.467 * * * \\
(0.645)\end{array}$ & $\begin{array}{l}-2.430 * * * \\
(0.651)\end{array}$ & $\begin{array}{l}-1.089 \\
(0.773)\end{array}$ & $\begin{array}{l}-0.926 \\
(1.008)\end{array}$ & $\begin{array}{l}-0.777 \\
(1.284)\end{array}$ \\
\hline Sickness leave & 0.028 & $\begin{array}{l}-0.183^{* * *} \\
(0.014)\end{array}$ & $\begin{array}{l}0.011 \\
(0.015)\end{array}$ & $\begin{array}{l}-0.031 * \\
(0.018)\end{array}$ & $\begin{array}{l}-0.045^{*} \\
(0.023)\end{array}$ & $\begin{array}{l}-0.050 \\
(0.032)\end{array}$ \\
\hline Disability insurance & 0.008 & $\begin{array}{l}-0.001 \\
(0.005)\end{array}$ & $\begin{array}{l}0.012 \\
(0.008)\end{array}$ & $\begin{array}{l}0.032 * * * \\
(0.012)\end{array}$ & $\begin{array}{l}0.044 * * \\
(0.018)\end{array}$ & $\begin{array}{l}0.081 * * * \\
(0.028)\end{array}$ \\
\hline$N$ unconditional & 47,185 & 47,185 & 47,185 & 47,185 & 47,185 & 47,185 \\
\hline$N$ sickness leave & 46,674 & 42,152 & 39,727 & 40,557 & 40,896 & 41,536 \\
\hline$N$ weekly hours & 45,063 & 36,386 & 36,787 & 37,385 & 37,999 & 39,081 \\
\hline \multicolumn{7}{|l|}{ Second child } \\
\hline Labor earnings & 415,809 & $\begin{array}{l}-184,840 * * * \\
(18,548)\end{array}$ & $\begin{array}{l}-120,923^{* * *} \\
(25,489)\end{array}$ & $\begin{array}{l}-62,890 * * \\
(28,672)\end{array}$ & $\begin{array}{l}-52,389 \\
(35,242)\end{array}$ & $\begin{array}{l}-52,644 \\
(38,397)\end{array}$ \\
\hline Employment & 0.868 & $\begin{array}{l}-0.177^{* * *} \\
(0.031)\end{array}$ & $\begin{array}{l}-0.186^{* * * *} \\
(0.044)\end{array}$ & $\begin{array}{l}-0.053 \\
(0.043)\end{array}$ & $\begin{array}{l}-0.016 \\
(0.049)\end{array}$ & $\begin{array}{l}-0.038 \\
(0.049)\end{array}$ \\
\hline Weekly hours & 33.036 & $\begin{array}{l}-3.002 * * * \\
(0.835)\end{array}$ & $\begin{array}{l}-3.226 * * * \\
(1.060)\end{array}$ & $\begin{array}{l}-2.362^{* * *} \\
(1.203)\end{array}$ & $\begin{array}{l}-4.222 * * * \\
(1.440)\end{array}$ & $\begin{array}{l}-3.376^{* *} \\
(1.377)\end{array}$ \\
\hline Sickness leave & 0.046 & $\begin{array}{l}-0.188^{* * * *} \\
(0.016)\end{array}$ & $\begin{array}{l}-0.029 \\
(0.022)\end{array}$ & $\begin{array}{l}-0.006 \\
(0.025)\end{array}$ & $\begin{array}{l}0.006 \\
(0.029)\end{array}$ & $\begin{array}{l}0.012 \\
(0.030)\end{array}$ \\
\hline Disability insurance & 0.011 & $\begin{array}{l}0.001 \\
(0.007)\end{array}$ & $\begin{array}{l}0.009 \\
(0.015)\end{array}$ & $\begin{array}{l}0.007 \\
(0.022)\end{array}$ & $\begin{array}{l}0.019 \\
(0.030)\end{array}$ & $\begin{array}{l}0.037 \\
(0.034)\end{array}$ \\
\hline$N$ unconditional & 21,639 & 21,639 & 21,639 & 21,639 & 21,639 & 21,639 \\
\hline$N$ sickness leave & 21,363 & 18,833 & 17,749 & 18,608 & 19,000 & 19,268 \\
\hline$N$ weekly hours & 20,584 & 16,289 & 16,491 & 17,429 & 17,984 & 18,320 \\
\hline \multicolumn{7}{|l|}{ Third child } \\
\hline Labor earnings & 414,211 & $\begin{array}{l}-141,317^{* * *} \\
(17,002)\end{array}$ & $\begin{array}{l}-94,975^{* * * *} \\
(22,357)\end{array}$ & $\begin{array}{l}-41,952^{*} \\
(24,437)\end{array}$ & $\begin{array}{l}-24,675 \\
(28,847)\end{array}$ & $\begin{array}{l}-31,650 \\
(26,152)\end{array}$ \\
\hline Employment & 0.878 & $\begin{array}{l}-0.188 * * * \\
(0.033)\end{array}$ & $\begin{array}{l}-0.195 * * * \\
(0.042)\end{array}$ & $\begin{array}{l}-0.055 \\
(0.038)\end{array}$ & $\begin{array}{l}-0.001 \\
(0.035)\end{array}$ & $\begin{array}{l}-0.023 \\
(0.033)\end{array}$ \\
\hline Weekly hours & 30.745 & $\begin{array}{l}-1.727 * * \\
(0.870)\end{array}$ & $\begin{array}{l}-1.121 \\
(0.969)\end{array}$ & $\begin{array}{l}-1.780 \\
(0.990)\end{array}$ & $\begin{array}{l}-1.772 \\
(1.023)\end{array}$ & $\begin{array}{l}-1.219 \\
(1.004)\end{array}$ \\
\hline Sickness leave & 0.049 & $\begin{array}{l}-0.092 * * * \\
(0.016)\end{array}$ & $\begin{array}{l}-0.054 * * * \\
(0.019)\end{array}$ & $\begin{array}{l}-0.007 \\
(0.019)\end{array}$ & $\begin{array}{l}0.008 \\
(0.020)\end{array}$ & $\begin{array}{l}0.016 \\
(0.021)\end{array}$ \\
\hline
\end{tabular}


Table 3 (continued)

\begin{tabular}{|c|c|c|c|c|c|c|}
\hline & \multirow{2}{*}{$\begin{array}{l}\text { Mean } \\
t=-2\end{array}$} & \multicolumn{5}{|c|}{ Second stage, 2SLS } \\
\hline & & $t=1$ & $t=2$ & $t=3$ & $t=4$ & $t=5$ \\
\hline Disability insurance & 0.011 & $\begin{array}{l}-0.029 * * * \\
(0.006)\end{array}$ & $\begin{array}{l}-0.034 * * * \\
(0.013)\end{array}$ & $\begin{array}{l}-0.044^{* *} \\
(0.019)\end{array}$ & $\begin{array}{l}-0.032 \\
(0.022)\end{array}$ & $\begin{array}{l}-0.006 \\
(0.024)\end{array}$ \\
\hline$N$ unconditional & 10,607 & 10,607 & 10,607 & 10,607 & 10,607 & 10,607 \\
\hline$N$ sickness leave & 10,396 & 8838 & 8246 & 8971 & 9297 & 9414 \\
\hline$N$ weekly hours & 10,042 & 7615 & 7642 & 8452 & 8845 & 9013 \\
\hline
\end{tabular}

2SLS estimates of the effect of the number of children on labor market outcomes. Each cell is a point estimate on the outcome indicated in the left column and the time period after the expected birth indicated in the column headers. The model is estimated separately for each parity $p=1-3$. Standard errors in parentheses. Separate estimates for the birth parities $p=1,2,3$ using miscarriages before the respective parity as instruments. Included covariates are indicator variables for age at the expected birth measured in months and calendar year, continent of origin and industry in $t=-2$. Significance indicated by asterisks: $* * * p<1$ percent, $* * p<5$ percent and $* p<10$ percent

after birth. A large part of the earnings and labor supply levels are recovered four to five years after childbirth. After five years, few effects are statistically significant. Coefficients, however, are still sizeable, especially after the first child, indicating that the effects are longer lasting. Earnings fall by 44, 19 and 20 percent in $t=1,2$ and 3 after the first birth, 44, 29 and 15 percent after the second birth and 34, 23 and 10 percent after the third birth. The size of the earnings effects is similar in size across birth parities in the first several years, but significantly smaller after the third child compared with the first two children. Employment at the extensive margin is reduced equally across all three parities: 18, 14 and 12 percent in $t=1,2$ and 3 after the first child, 18, 19 and 5 percent after the second child and 19, 19 and 6 percent after the third child. Employment at the intensive margin (weekly hours conditional on employment) is reduced 10, 7 and 3 percent after the first child, 9, 10 and 7 percent after the second child and 6, 4 and 6 percent after the third child. Thus, the larger effect on earnings after the two first children is driven in part by larger reductions in the labor supply on the intensive margin.

The labor market effects of the first and second child are also more persistent. The effects on earnings and employment at the extensive margin are still statistically significant and sizeable five years after the birth of the first child, and the effects on labor supply at the intensive margin are still statistically significant five years after the birth of the second child (which for most families is the last child). The long-term evidence in Fig. 8 in the Appendix suggests that the effects on earnings and labor supply at the extensive margin are still present ten years later for the first child at the extensive margin and for the second child at the intensive margin, although the estimates are highly imprecise in the longer run. The short-term nature of employment and earnings effects of the third child are consistent with the findings by Cools and Markussen (2017) who use the same-sex instrument to estimate the effect of the third child on Norwegian data from the same period. We estimated the models separately 
for women with high and low educational levels, according to earnings in $t=-2$ and according to age, but find no statistically significant heterogeneity of effects along these dimensions.

Having children also affects whether or not one receives health-related welfare benefits. Sickness leave, which increased strongly during pregnancy, decreases in the first year after birth (when most of the women who gave birth are on parental leave and those who miscarried have a high probability of being pregnant). In $t=3$ and $t=4$, sickness leave decreases after the birth of the first child and is not significantly affected after the birth of the second and third child. Isolated, this result contradicts theories about a female "double burden" that increases sickness leave for working women with children. The probability of receiving a disability insurance is, however, affected from $t=3$ after the first birth. Having the first child seems to push some women out of employment and on to disability insurance. Some of the fall in sickness absence after the first child may therefore be due to sorting of women with poor health out of employment. The standard errors are large (especially in the longer term, see Fig. 8); thus, the size of the estimate should be interpreted with caution. After the third child, there is a short-term reduction in sickness leave and the probability of receiving disability insurance indicating no double burden effects of having three or more children.

The similarity of effects across the first and second child differs slightly from the results for Danish women in Lundborg et al. (2017) who find a larger marginal effect of the first compared with the second child-in the short and long term. Some of the longer-term difference might, however, be due to differences in the specification of the independent variable. Lundborg et al. (2017) use "have child" indicators whereas we use "number of children." The choice of the independent variable in the IV specification affects only the scaling of the reduced form effects. The "have child" indicators scale the effects only according to the probability of having the $p$ th parity child (including therefore also eventual effects of later children), but using "number of children" scales the effects by the number of children. ${ }^{16}$

Figure 4 displays the effect of motherhood on the probability of having earnings above seven different earnings thresholds displayed on the $x$-axis, ranging from NOK 100,000 to 700,000 (the outcome variables are indicator variables equal to zero if yearly earnings are below the indicated limit, and one if they are above). We show the results from the first five years after birth, indicated in the figure headings. In the first year after childbirth, there is no statistically significant effect of having the first, second or third child on the lowest earnings threshold. The effect is relatively

\footnotetext{
${ }^{16}$ We have also estimated the model using "have child" indicators and the effects are overall larger and more long-term using the "have child" indicators compared with a "number of children" specification. This is as expected, as the difference between the birth and the miscarriage group in the probability of having the $p$ th parity child grows smaller over time, and differences in labor market outcomes are therefore divided by increasingly smaller numbers over time. There is a larger persistence over time in the difference in number of children because most couples continue having more children, especially after the first child. It is also consistent with Angrist and Evans (1998) who find that the estimates using "number of children" are about $0.75-0.78$ as large as the estimates using a "more than 2 children" indicator when they use the same-sex instrument to estimate the effect of third children.
} 
small also for the earnings threshold NOK 200,000, which we used as an employment indicator in the main results. This means that the effects on labor supply at the extensive margin are quite small. The small effects for low earnings thresholds also indicate that women who are marginally employed do not reduce their labor supply by much after having children. When we increase the earnings threshold, the effect of children becomes larger. The effect is largest around NOK 300,000 to 500,000. Thus, the main effect on female labor supply is the increased probability of working less at the intensive margin and dropping below earnings thresholds in the middle of the earnings distribution. ${ }^{17}$ There are also small effects of the first three children on the probability of earning above NOK 700,000, which is approximately the 85th percentile in the earnings distribution. Women with high earnings reduce their labor supply because of children to less of an extent than women in the middle part of the income distribution.

The fall in the probability of earning above the different thresholds is largest in the first years, consistent with the main results. The average negative effects of the second child in Table 3 hides, however, heterogeneity of effects along the income distribution. The effects on lower earnings thresholds are actually positive 3 years after birth, which indicates an intertemporal substitution of labor supply for women in the lower layers of the earnings distribution.

\subsection{Fathers' labor market outcomes}

We also estimated the IV model for fathers. This is estimated on a restricted sample of married and cohabiting men in year $t=-2$, because we cannot observe fathers who lose a child due to miscarriage in the data. The results for women in the married sample are similar to the results in the full sample of women in Table $3 .{ }^{18}$

The results are displayed in Table 4. We find that having children affects men less than women. However, we find indications that men's labor supply and earnings are positively, rather than negatively affected. There are positive earnings and employment effects after the first and second child, with more statistically significant coefficients after the second child. The positive effects on earnings seem to be driven by employment effects at the extensive margin, and not by fathers working longer hours. However, overtime is not well captured in the hours measure, and these estimates may understate the true effect on hours at the intensive margin (which is also supported by the larger point estimates on earnings). ${ }^{19}$ Together, the negative effects on employment for mothers, and the positive effects on employment for fathers, imply that families shift toward a traditional division of labor when they have their first and second child. In families who go on to have a third child, there are indications that men share some of the decrease in employment and earnings, but among those who are employed, weekly work hours are positively affected. There is hardly any effect on sickness leave and disability insurance in the father sample.

\footnotetext{
${ }^{17}$ Mean earnings in $j=-2$ is 461,344 before the first birth and 415,809 and 414,211 before the second and third births, respectively. The full distribution of earnings in $j=-2$ is shown in Fig. 9 in the Appendix.

${ }^{18}$ Results available upon request.

${ }^{19}$ Men more often work full-time before birth and have to work overtime to increase their hours.
} 


\section{First birth}

Years after planned birth

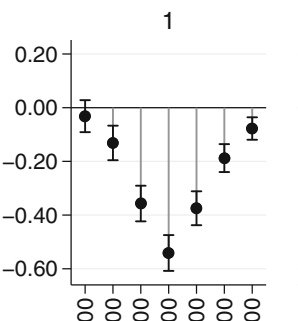

2

3

4

5
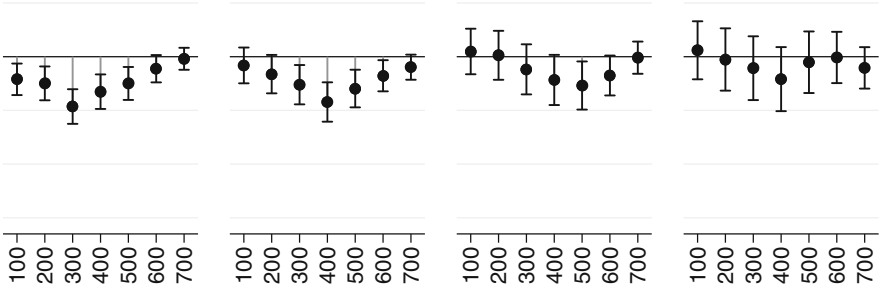

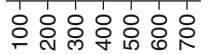

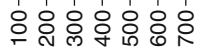

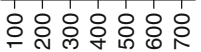

Labor earnings threshold (NOK 1.000)

Second birth

Years after planned birth

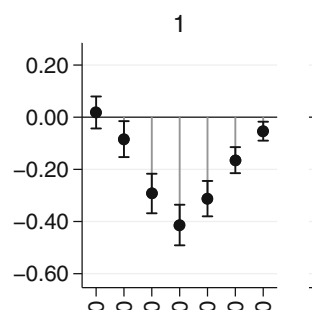

2

3

4

5
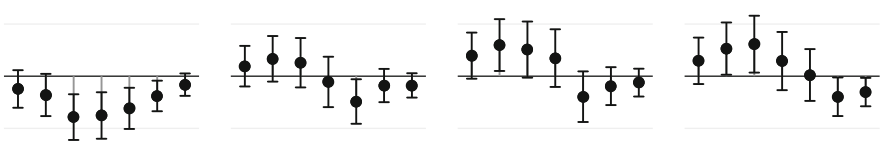

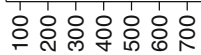

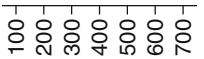

웅유융웅ㅇํㅇㅇㅇㅇㅇ

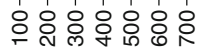

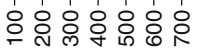

Labor earnings threshold (NOK 1.000)

Third birth

Years after planned birth

2

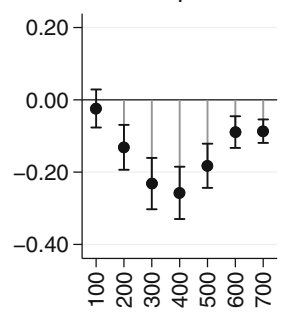

3

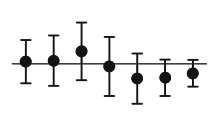

4

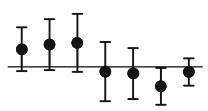

5

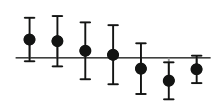

Fig. 4 IV estimates of the effect of the number of children on seven different earnings cutoffs. $t=0$ is the year of the expected birth. Each filled circle indicates the estimated effect of the number of children on the probability of earning above the earnings threshold indicated on the $x$-axis (from NOK 100,000 to 700,000). The effects are estimated separately for each time period indicated in the panel headings, and each parity $p=1-3$. Included covariates are indicator variables for age at the expected birth measured in months and calendar year, continent of origin and industry in $t=-2$. Error bars show $95 \%$ confidence intervals 
Table 4 IV estimates of the effect of the number of children on labor market outcomes, fathers

\begin{tabular}{|c|c|c|c|c|c|c|}
\hline & \multirow{2}{*}{$\begin{array}{l}\text { Mean } \\
t=-2\end{array}$} & \multicolumn{5}{|c|}{ Second stage, 2SLS } \\
\hline & & $t=1$ & $t=2$ & $t=3$ & $t=4$ & $t=5$ \\
\hline \multicolumn{7}{|l|}{ First child } \\
\hline Labor earnings & 618,121 & $\begin{array}{l}5,227 \\
(85,434)\end{array}$ & $\begin{array}{l}45,693 \\
(217,636)\end{array}$ & $\begin{array}{l}39,840 \\
(113,430)\end{array}$ & $\begin{array}{l}111,245 \\
(183,618)\end{array}$ & $\begin{array}{l}91,298 \\
(279,018)\end{array}$ \\
\hline Employment & 0.872 & $\begin{array}{l}0.070 \\
(0.045)\end{array}$ & $\begin{array}{l}0.059 \\
(0.042)\end{array}$ & $\begin{array}{l}0.075 \\
(0.053)\end{array}$ & $\begin{array}{l}0.113 * \\
(0.064)\end{array}$ & $\begin{array}{l}0.132 \\
(0.090)\end{array}$ \\
\hline Weekly hours & 36.387 & $\begin{array}{l}0.580 \\
(0.820)\end{array}$ & $\begin{array}{l}-0.080 \\
(0.751)\end{array}$ & $\begin{array}{l}0.579 \\
(1.046)\end{array}$ & $\begin{array}{l}1.081 \\
(1.187)\end{array}$ & $\begin{array}{l}2.143 \\
(1.577)\end{array}$ \\
\hline Sickness leave & 0.022 & $\begin{array}{l}-0.004 \\
(0.019)\end{array}$ & $\begin{array}{l}0.036^{*} \\
(0.018)\end{array}$ & $\begin{array}{l}-0.006 \\
(0.024)\end{array}$ & $\begin{array}{l}-0.009 \\
(0.029)\end{array}$ & $\begin{array}{l}0.083 \\
(0.051)\end{array}$ \\
\hline Disability insurance & 0.016 & $\begin{array}{l}-0.023 \\
(0.023)\end{array}$ & $\begin{array}{l}-0.008 \\
(0.023)\end{array}$ & $\begin{array}{l}-0.010 \\
(0.031)\end{array}$ & $\begin{array}{l}-0.006 \\
(0.039)\end{array}$ & $\begin{array}{l}-0.007 \\
(0.056)\end{array}$ \\
\hline$N$ unconditional & 17,537 & 17,537 & 17,537 & 17,537 & 17,537 & 17,537 \\
\hline$N$ sickness leave & 16,010 & 16,091 & 16,111 & 16,272 & 16,316 & 16,344 \\
\hline$N$ weekly hours & 14,941 & 14,971 & 14,966 & 15,067 & 15,043 & 15,083 \\
\hline \multicolumn{7}{|l|}{ Second child } \\
\hline Labor earnings & 661,060 & $\begin{array}{l}51,082 \\
(48,045)\end{array}$ & $\begin{array}{l}123,201 * \\
(66,664)\end{array}$ & $\begin{array}{l}167,250 \\
(110,030)\end{array}$ & $\begin{array}{l}176,413 \\
(122,888)\end{array}$ & $\begin{array}{l}195,717 \\
(154,285)\end{array}$ \\
\hline Employment & 0.927 & $\begin{array}{l}0.087 * * * \\
(0.032)\end{array}$ & $\begin{array}{l}0.072 * \\
(0.041)\end{array}$ & $\begin{array}{l}0.062 \\
(0.046)\end{array}$ & $\begin{array}{l}0.104 * * \\
(0.049)\end{array}$ & $\begin{array}{l}0.066 \\
(0.050)\end{array}$ \\
\hline Weekly hours & 36.592 & $\begin{array}{l}-0.372 \\
(0.614)\end{array}$ & $\begin{array}{l}-0.278 \\
(0.697)\end{array}$ & $\begin{array}{l}0.379 \\
(0.778)\end{array}$ & $\begin{array}{l}-0.488 \\
(0.861)\end{array}$ & $\begin{array}{l}0.665 \\
(0.887)\end{array}$ \\
\hline Sickness leave & 0.027 & $\begin{array}{l}0.010 \\
(0.017)\end{array}$ & $\begin{array}{l}0.028 \\
(0.020)\end{array}$ & $\begin{array}{l}0.016 \\
(0.022)\end{array}$ & $\begin{array}{l}0.013 \\
(0.025)\end{array}$ & $\begin{array}{l}0.026 \\
(0.026)\end{array}$ \\
\hline Disability insurance & 0.023 & $\begin{array}{l}-0.036^{*} \\
(0.020)\end{array}$ & $\begin{array}{l}-0.034 \\
(0.026)\end{array}$ & $\begin{array}{l}-0.049 \\
(0.031)\end{array}$ & $\begin{array}{l}-0.033 \\
(0.034)\end{array}$ & $\begin{array}{l}-0.033 \\
(0.036)\end{array}$ \\
\hline$N$ unconditional & 11,946 & 11,946 & 11,946 & 11,946 & 11,946 & 11,946 \\
\hline$N$ weekly hours & 10,317 & 10,241 & 10,100 & 10,095 & 10,140 & 10,189 \\
\hline$N$ sickness leave & 11,134 & 11,078 & 10,995 & 11,035 & 11,120 & 11,145 \\
\hline \multicolumn{7}{|l|}{ Third child } \\
\hline Labor earnings & 680,033 & $\begin{array}{l}-32,021 \\
(46,226)\end{array}$ & $\begin{array}{l}-65,092 \\
(63,963)\end{array}$ & $\begin{array}{l}-11,111 \\
(115,798)\end{array}$ & $\begin{array}{l}-45,593 \\
(109,879)\end{array}$ & $\begin{array}{l}-14,312 \\
(72,918)\end{array}$ \\
\hline Employment & 0.932 & $\begin{array}{l}-0.016 \\
(0.027)\end{array}$ & $\begin{array}{l}-0.006 \\
(0.030)\end{array}$ & $\begin{array}{l}-0.049 \\
(0.032)\end{array}$ & $\begin{array}{l}-0.002 \\
(0.032)\end{array}$ & $\begin{array}{l}-0.004 \\
(0.031)\end{array}$ \\
\hline Weekly hours & 36.633 & $\begin{array}{l}0.255 \\
(0.466)\end{array}$ & $\begin{array}{l}1.139 * * \\
(0.527)\end{array}$ & $\begin{array}{l}0.319 \\
(0.578)\end{array}$ & $\begin{array}{l}1.343 * * \\
(0.575)\end{array}$ & $\begin{array}{l}0.819 \\
(0.576)\end{array}$ \\
\hline Sickness leave & 0.032 & $\begin{array}{l}0.003 \\
(0.014)\end{array}$ & $\begin{array}{l}-0.007 \\
(0.015)\end{array}$ & $\begin{array}{l}-0.008 \\
(0.015)\end{array}$ & $\begin{array}{l}0.019 \\
(0.015)\end{array}$ & $\begin{array}{l}0.024 \\
(0.017)\end{array}$ \\
\hline
\end{tabular}


Table 4 (continued)

\begin{tabular}{llllllll}
\hline & Mean & & \multicolumn{2}{l}{ Second stage, 2SLS } \\
\cline { 2 - 5 } \cline { 5 - 7 } & $t=-2$ & & $t=1$ & $t=2$ & $t=3$ & $t=4$ & $t=5$ \\
\hline Disability insurance & 0.030 & 0.003 & 0.004 & 0.001 & -0.029 & 0.006 \\
& & $(0.019)$ & $(0.022)$ & $(0.024)$ & $(0.024)$ & $(0.024)$ \\
$N$ unconditional & 8196 & 8196 & 8196 & 8196 & 8196 & 8196 \\
$N$ weekly hours & 6942 & 6879 & 6834 & 6861 & 6865 & 6897 \\
$N$ sickness leave & 7609 & 7551 & 7530 & 7546 & 7567 & 7619 \\
\hline
\end{tabular}

2SLS estimates of the effect of the number of children on labor market outcomes. Each cell is a point estimate on the outcome indicated in the left column and the time period after the expected birth indicated in the column headers. The model is estimated separately for each parity $p=1-3$. Standard errors in parentheses. Separate estimates for the birth parities $p=1,2,3$ using miscarriages before the respective parity as the instruments. Included covariates are indicator variables for age at the expected birth measured in months and calendar year, continent of origin and industry in $t=-2$. Significance indicated by asterisks: $* * * p<1$ percent, $* * p<5$ percent and $* p<10$ percent

The point estimates are large for fathers' earnings, especially after the second child. Together with the point estimates for mothers' earnings, the results imply that it is primarily the first and the second child that shift the household labor supply in a traditional direction, with increasing intra-household earnings inequality. Having children does not, however, affect total household earnings negatively in the long run. The long-term decrease in mothers' earnings is compensated by the long-term increase in fathers' earnings. After the birth of the second (and for most, the last) child, the sum of mothers' and fathers' income effects is even positive, suggesting that the household as a whole recovers some of the short-term earnings loss by increasing their labor supply when their children are older. ${ }^{20}$

\section{Exclusion and sensitivity}

\subsection{Direct effects of miscarriage (exclusion)}

A particular concern with using miscarriage as an instrumental variable is that it may affect women in more ways than through fertility. If a woman experiences psychological distress after the miscarriage, this can have negative career consequences. The medical literature compares the period after a miscarriage to a period of grief where feelings of depression and anxiety are most pronounced during the first six months

\footnotetext{
${ }^{20}$ The positive long-term effects on total household earnings are robust to estimating the effects of children on the intra-household sum of earnings, instead of separately for mothers and fathers. Results available upon request.
} 
after the experience and then taper off, gradually going back to "normal" after a year (Broen et al. 2004; Lok et al. 2010) or six months found by others (Brier 2008).

The event study graphs in Figs. 2 and 3 provide indications of whether there is a direct effect of a miscarriage on labor market outcomes. Changes in labor market outcomes for the miscarriage group also in $t=0$ (expected birth) may indicate that the miscarriage has a direct effect. However, as we saw in Fig. 1, in $t=0$ some women in the miscarriage group have given birth across all birth parities. Changes in labor market outcomes in $t=0$ may also reflect effects of having children. Eventual direct effects of the miscarriage may include psychological distress, negative employment effects of new pregnancies or negative employment effects of children for those who have children already in $t=0$.

In Fig. 2, earnings, employment and hours do not decrease in $t=0$ in the miscarriage group. For the health and welfare outcomes in Fig. 3, sickness leave rates in $t=0$ are lower for those who miscarry than for those who give birth (who are heavily absent during pregnancy). We also see that those who miscarry have higher sickness leave rates in $t=1$. Much of this may be attributed to new pregnancies.

We wish to get an indication of whether differences between the birth and miscarriage groups in $t=0$ are direct effects of the miscarriage or instead new pregnancies. To obtain this, we split the group that miscarried in three based on when they have a new child, as depicted in Fig. 5. We use only miscarriages before first births to have enough observations in all three groups. The three groups are (1) those who have a new child in $t=0$ (indicated by open circles in the figure), (2) those who have a child in year $t=1$ (triangles) and (3) those who have a child later than $t=1$ or never during the observational period (squares). ${ }^{21}$

The results are displayed in Fig. 5. In the left panel, we see that the fertility pattern in the different groups is consistent with the way we split the sample: Group 1 has children in the same year as the birth group (but have their next child earlier). Groups 2 and 3 follow the same fertility pattern one and three years later, respectively.

In the middle panel, we show the results for employment. Employment rates are at their highest in $t=0$ across all groups because we condition on employment during pregnancy. Employment in group 1 is almost at the same track as the group who gives birth, indicating no "extra" effect of the miscarriage for those who have a child in the same year as first expected. Employment in groups 2 and 3 is negatively affected only later, as expected. Employment in $t=1$ is not different from employment in $t=-1$, indicating no direct effect of the miscarriage on employment in these groups.

In the right panel, we show the results for sickness leave. Again, we see that group 1 (those who miscarry, but have a child in $t=0$ ) have almost the same sickness leave pattern as those who give birth. This holds for all the 5 years following the first and second birth, except for higher absence in $t=0$ which might capture the sickness leave in relation to the miscarriage. This indicates no direct effect of the miscarriage

\footnotetext{
${ }^{21}$ Note that the timing of a new child is not purely exogenous: It is up to the parents if they want to try again, and when. The endogenous timing of new children makes our split according to timing endogenous as well, and therefore the test is not perfect. Note also that some of the groups are very small after this split, which means there is potentially a small sample bias. Sample size: 46,421 give birth, 369 are in group 1, 529 in group 2 and 195 in group 3.
} 


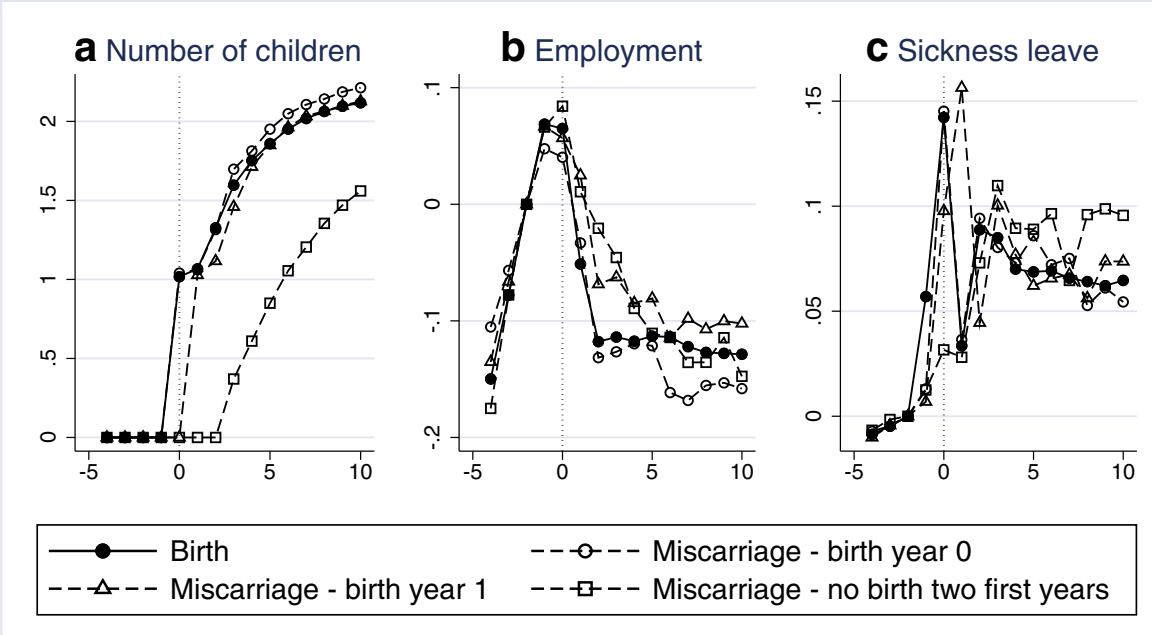

Fig. 5 Event study graphs showing labor market outcomes before and after the expected first birth, dividing the group that miscarried into three groups based on the timing of new children. Event time $=0$ is the year of the expected birth. Those who give birth as expected indicated by filled circles $(N=46,421)$. Sample split in the group that miscarried according to the timing of new children: (1) those who have a new child in $t=0$, open circles $(N=369)$, (2) those who have a child in year $t=1$, triangles $(N=529)$ and (3) those who have a child later than $t=1$ or never during the observational period, squares $(N=195)$. Included covariates are indicator variables for age at the expected birth measured in months and calendar year, continent of origin and industry in $t=-2$

after $t=0$ in group 1 . In group 3, there are some indications of a direct effect, as they have higher absence rates in the longer run. This may, however, also be due to higher probabilities of being pregnant (as this is the group where fertility is most postponed). Given the evidence, the few observations and potential selectivity of the sample split, there is, according to our best judgment few indications that miscarriages have direct labor market effects.

Miscarriage may have especially large direct effects if the woman experiences repeated miscarriages and/or ends up not having a child. In both cases, the strain may be larger and have long-term direct effects on labor market outcomes. We estimate the main model excluding two groups potentially most negatively affected by a miscarriage, namely, (1) those who experience repeated miscarriages and (2) those who never end up having the expected child. The results are reported in Figs. 10 and 11 in the Appendix, and the results are almost exactly the same, providing further evidence that negative direct effects of the miscarriage do not bias the results.

\subsection{Couple stability as causal channel}

The estimated effects on labor market outcomes are total effects of children, which might work through several channels. The most important one is presumably that 
parents have to spend time caring for the child. There may, however, be other causal channels. A miscarriage and having children may, e.g., influence couple stability. Some of the differences in labor market outcomes in the following years may be due to differences in the probability of being married, and an eventual effect of being married or divorcing on labor market outcomes.

In Fig. 6, we used the same event study framework that we used earlier and study changes in marriage probabilities following birth and miscarriage. The similar pretrends for this outcome are reassuring regarding the exogeneity of miscarriage. In the full sample, there are few statistically significant differences between the birth and miscarriage groups before and after the expected birth. Marriage probabilities are lower for the miscarriage group after the expected second birth, but it is not obvious which of the groups changes paths after $t=0$. When we split the sample according to marital status in $t=-5$ in the two lower panels, the patterns are clearer. The differences in marriage probabilities are driven by changing divorce trends in the group that gives birth. The group that was married in $t=5$ is on a negative trend, and the group that miscarries continues on the same trend-indicating no direct effect of the miscarriage. The group that has children, however, reverses the trend. It seems that having the first, second and third child reduces the risk of divorce. As with the labor market outcomes, the trend also reverses for the miscarriage group-only later (when they have children). The group that was not married in $t=-5$, has a higher probability of being married after the first and second child, similar for the birth and miscarriage groups. After third births, however, the trends diverge. It is not clear whether this is driven by a direct negative effect of miscarriages or a direct positive effect of having children.

To evaluate the marginal effect of each parity child on marriage probabilities, we need to adjust the differences between the birth and miscarriage group according to the differences in the number of children, equivalent to the labor market analysis. In Fig. 12 in the Appendix, we report the IV estimates of the effect of the number of children on the probability of being married the first five years after the expected birth, for the full sample and splitting the sample according to marital status in $t=-2$. We find that there is no effect of the number of children on marriage probabilities after the first child. After the second and third child, there is a positive effect of the number of children on marriage probabilities of almost the same size (10 percent). Previous literature on the effects of divorce on female labor supply (see, e.g., Bargain et al. 2012; Bonnet et al. 2020), has found that divorce increases women's labor supply. Given that the effects of divorce are in the same direction in our sample, the results indicate that the marginal effects of the second and third child would be smaller absent the effect on marriage probabilities.

\subsection{Composition of women across birth parities}

Divorce may also affect the composition of parents across birth parities and influence the interpretation of differences in the marginal effects of the first, second and third child. Those who then have two children are parents who have not divorced or left each other, and if there is heterogeneity of effects across more and less stable couples, the similar marginal effects between first and second births that we find may not be 


\section{Unconditional}
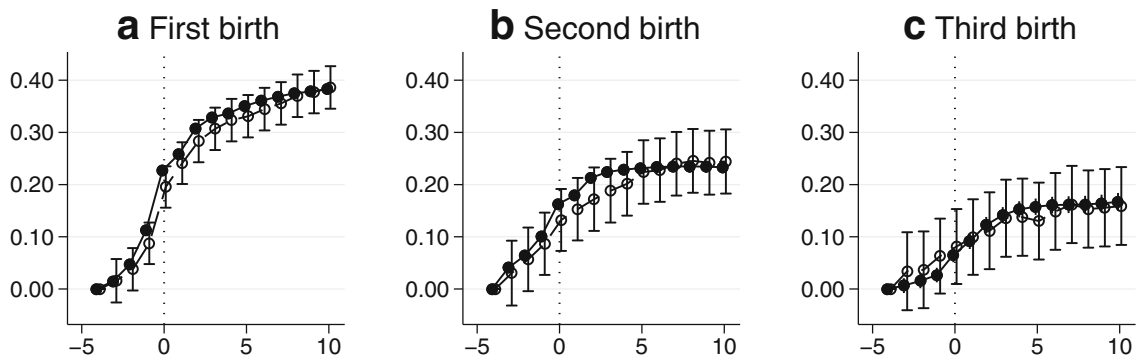

\section{Married in $\mathrm{t}-5$}
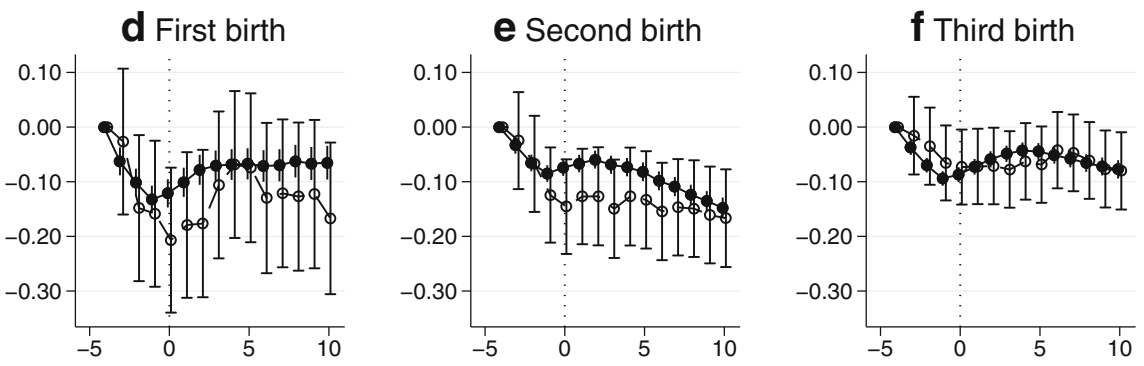

Not married in $\mathrm{t}-5$

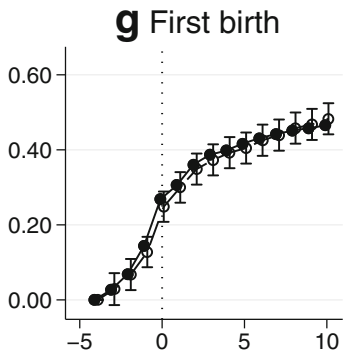

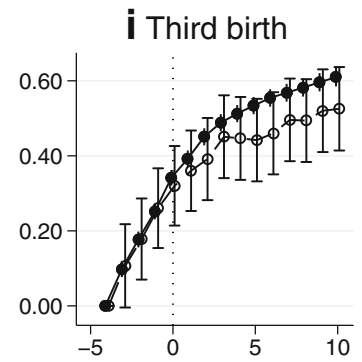

\section{$\rightarrow$ Birth $\quad$ - . Miscarriage}

Fig. 6 Event study graphs showing marriage probabilities before and after the expected birth, birth and miscarriage groups separately; by marital status in $t=-5$. OLS estimates of the effect of miscarriage on marriage probabilities. Each mark is a point estimate in the time period after expected birth indicated on the $x$-axis. Separate estimates for the birth parities $p=1,2,3$. Included covariates are indicator variables for age at the expected birth measured in months and calendar year, continent of origin and industry in $t=-2$. Error bars show $95 \%$ confidence intervals 
representative of all couples. To check the sensitivity of the results to such compositional changes, we estimate the effect of the first child for the full sample ("stable" and "unstable" couples) and a sample of women who have more than one child or at least two ("stable" couples). The results are reported in Fig. 10 in the Appendix. The point estimates are slightly larger for those who have at least two children, but the results are not statistically significantly different from each other. This means that the effects of having the second child may potentially be smaller for those who have only one child, but this is impossible to test. There will always be observed or unobserved differences among those who have one, two or three children, which one should keep in mind when interpreting the results.

There may also be other compositional differences affecting the size of the marginal effects across birth parities. Another example is that there are more students in the group who has their first child, and students may from the outset work less and be less affected by having children. Because we condition on employment, however, there are not many students in this sample. To check the sensitivity of the results to this kind of compositional difference, we estimate the model without students. The results are reported in Fig. 11 in the Appendix. The effect is negligible.

\section{Conclusion}

In this paper, we estimated the effect of the first three children on women's and men's labor market outcomes and on the probability of receiving health-related welfare benefits. We use miscarriages as a fertility shock to the timing of children, giving rise to differences in the number of children between women who are otherwise similar. Miscarriages occur at all birth parities, and thus, we are able to estimate the marginal effects of children after the first, second and third birth (higher-order births are less common in Norway).

We find that each of the first three children causes large drops of almost the same size in employment and earnings in the first three years, but slightly smaller after the third child. A large part of the initial drop is quickly recovered, but a persistent effect on labor supply and earnings remains after the first and second child. The longer-term evidence is less conclusive, but suggests that earnings catch up after the second and third child. We cannot, however, rule out a more persistent effect of the first child, as the point estimate is not statistically significant, but still sizeable and negative ten years after birth. The probability of receiving a disability insurance increases after the birth of the first child, indicating that some of the long-term effects on women's employment may be due to negative health effects.

Male earnings are positively affected by the first and second child, but statistically significantly only for the second (and for most, the last) child. Norwegian households, therefore, move toward a "traditional" division of labor after having children, and the second child seems even more important than the first. For the household as a whole, the positive impact on fathers' earnings compensate for the negative impact on mothers' earnings, and the sum of household earnings is not negatively affected in the longer term. After the second and third child, we also find positive effects on the probability of staying married, which indicates that higher couple stability plays 
a role as a causal channel for the relatively large labor market effects of children two and three.

Acknowledgement We would like to thank Sara Cools, Simen Gaure, Jo Thori Lind, Kalle Moene, Magne Mogstad, Ole Røgeberg, Ragnhild Schreiner and Kjetil Storesletten for their useful comments on a previous version of the paper. We also thank Editor Shuaizhang Feng, two anonymous referees and seminar participants at the University of Oslo, EALE2014, AEA2015, EEA2014 and Workshop in Family Economics, Copenhagen 2015 for their helpful comments and suggestions. This paper is part of the projects "Absenteeism - Disability, Norms and Interventions" (grant 201416), "Disentangling absence patterns" (grant 227103) and "Understanding the gender gap in sickness absence" (grant 218378), financed by the Norwegian Research Council. Data made available by Statistics Norway were essential for the research project.

\section{Compliance with ethical standards}

Conflict of interest The authors declare that they have no conflicts of interest

\section{Appendix}

a First birth

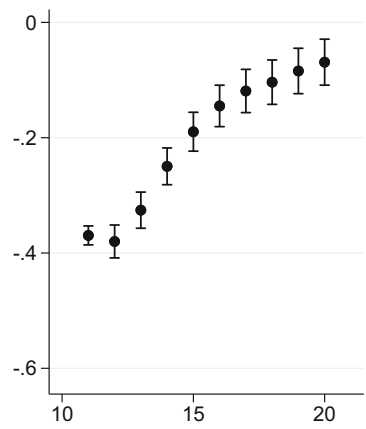

b Second birth

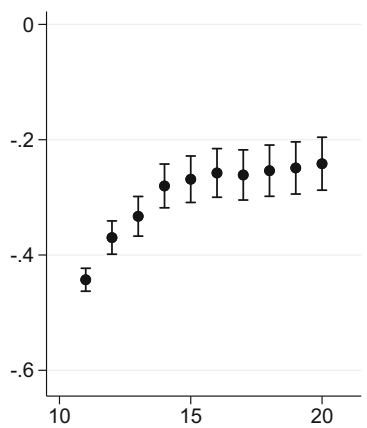

C Third birth

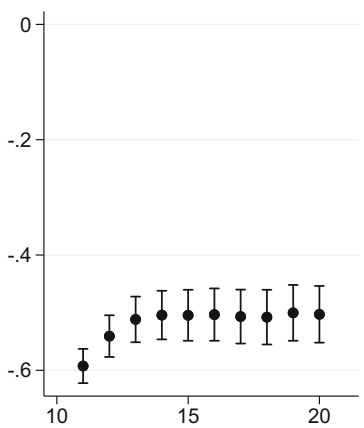

Fig. 7 First stage effects of miscarriage on number of children. Separate estimates for the birth parities $p=1,2,3$ using miscarriages before the respective parity as the dependent variable. Each mark is a point estimate on the outcome indicated in the sub-figure header and the time period after the expected birth indicated on the $x$-axis. Included covariates are indicator variables for age at the expected birth measured in months and calendar year, continent of origin and industry in $t=-2$. Error bars show $95 \%$ confidence intervals 


\section{Labor earnings $(1,000 \mathrm{NOK})$}

First birth

Second birth

Third birth
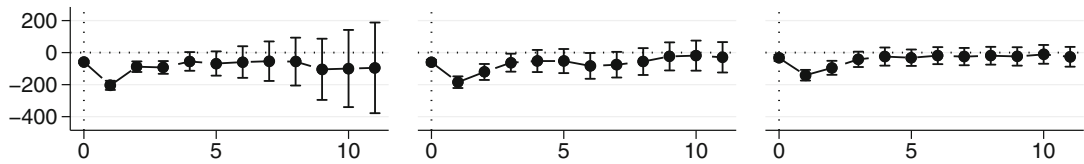

Years after planned birth

\section{Employment}

First birth

Second birth

Third birth
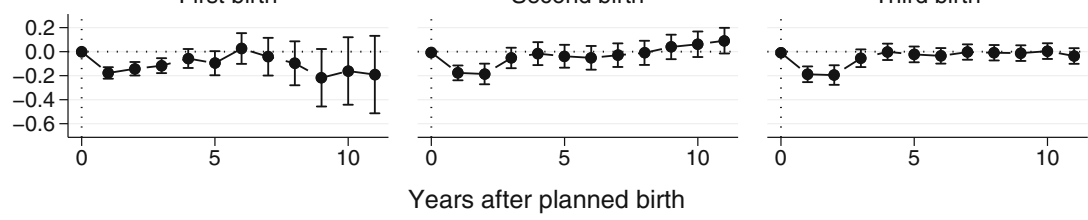

Weekly work hours - cond. on employment

First birth

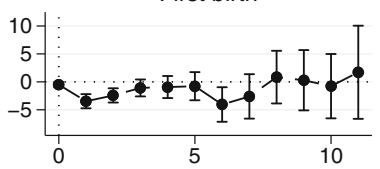

Second birth

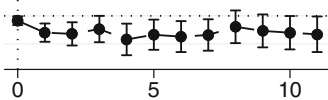

Years after planned birth
Third birth

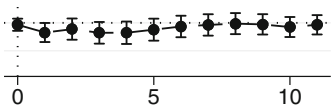

Sickness leave

First birth

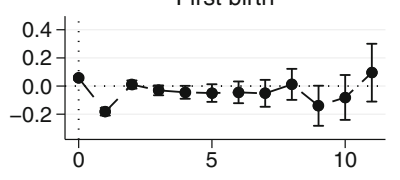

Second birth

Third birth
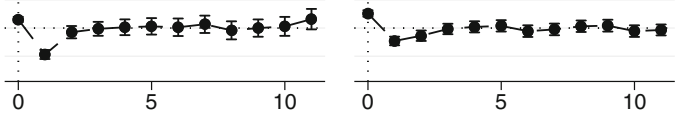

Years after planned birth

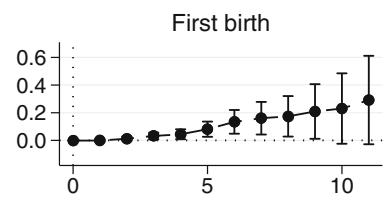

Disability insurance

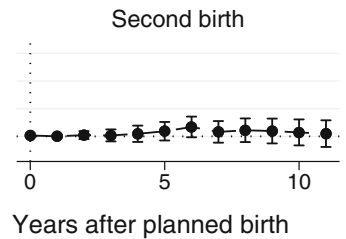

Third birth

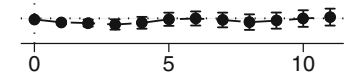

Fig. 8 IV estimates of the effect of the number of children on labor market outcomes, 1-10 years after the expected birth. 2SLS estimates of the effect of the number of children on labor market outcomes. Each mark is a point estimate on the outcome indicated in the sub-figure header and the time period after the expected birth indicated on the $x$-axis. Separate estimates for the birth parities $p=1,2,3$ using miscarriages before the respective parity as the instruments. Included covariates are indicator variables for age at the expected birth measured in months and calendar year, continent of origin and industry in $t=-2$. Error bars show $95 \%$ confidence intervals 


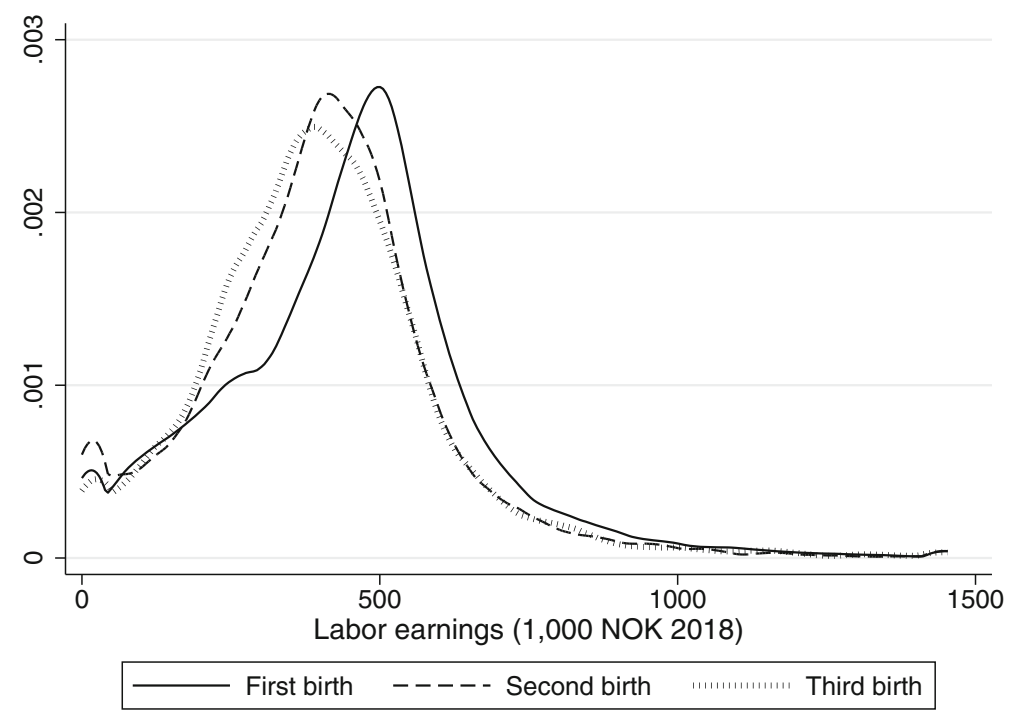

Fig. 9 The earnings distribution in $t=-2$. Kernel density estimate of the earnings distribution in $t=-2$ 
a Earnings

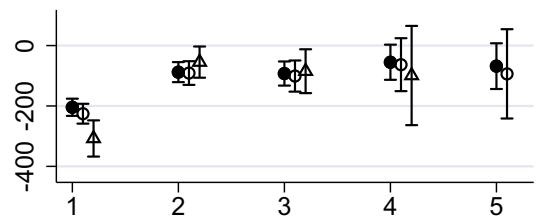

c Hours worked (if employed)

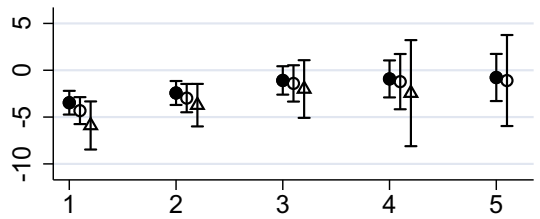

e Disability insurance

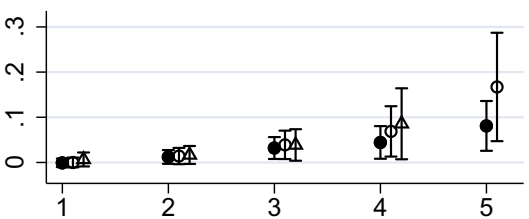

b Employment

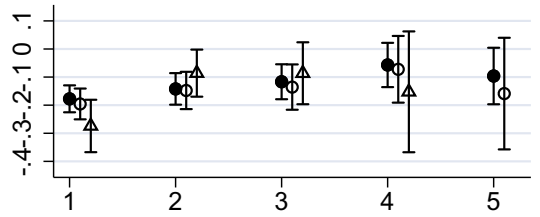

d Sickness leave

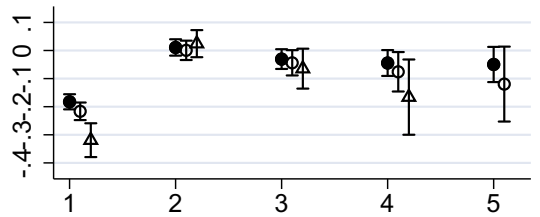

\section{- All $\quad$ At least one child $\Delta$ More than one child}

Fig. 10 IV estimates of the effect of the number of children on labor market outcomes; by completed fertility. 2SLS estimates of the effect of the number of children on labor market outcomes. Each mark is a point estimate on the outcome indicated in the sub-figure header and the time period after expected birth indicated on the $x$-axis. Estimates only for first births, using miscarriage before first birth as the instrument. The sample is split according to completed fertility, and the model is estimated separately for those who end up having only one child during the time window (open circle), and those who end up having more than one child (open triangle). Included covariates are indicator variables for age at the expected birth measured in months and calendar year, continent of origin and industry in $t=-2$ 


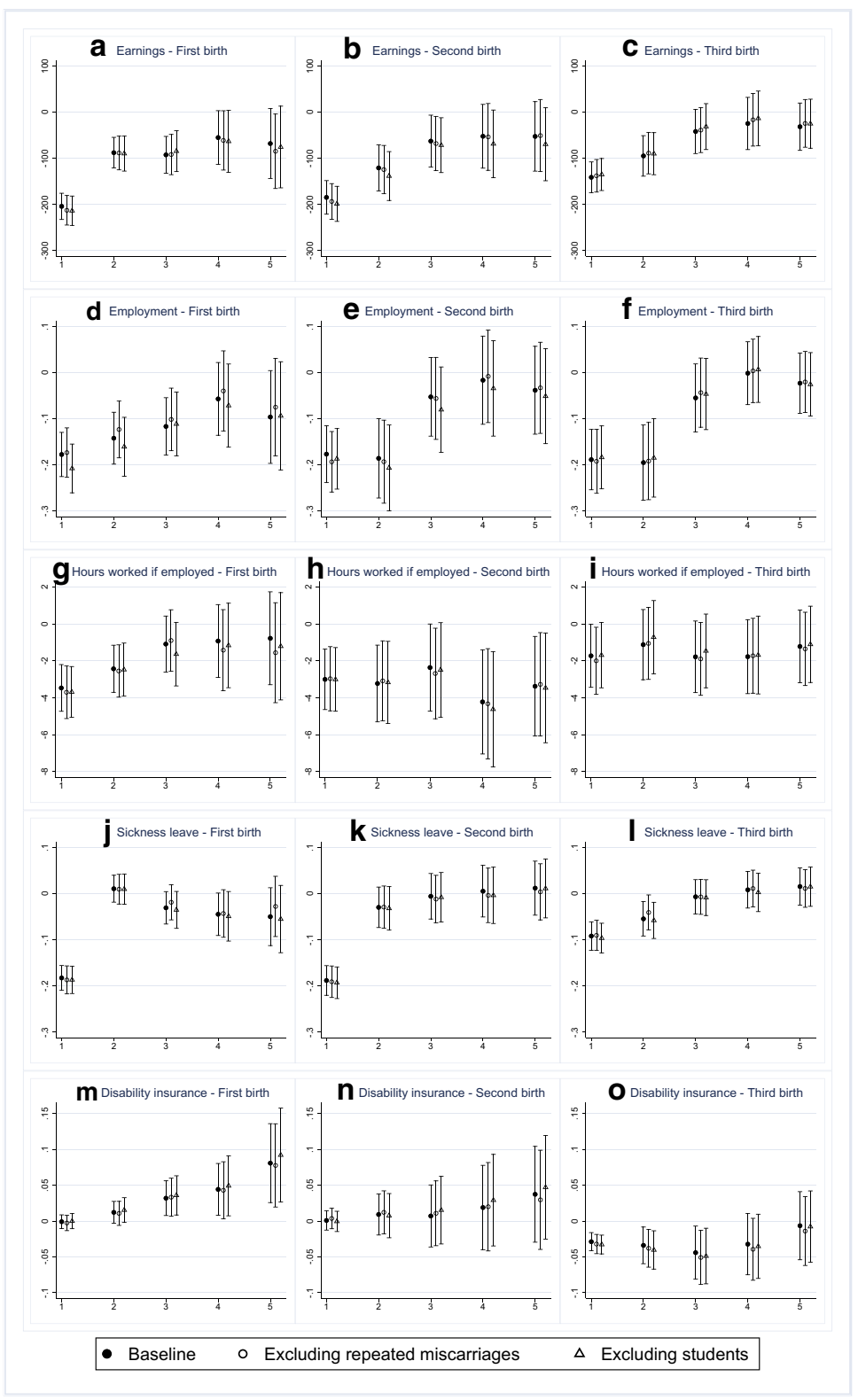

Fig. 11 IV estimates of the effect of the number of children on labor market outcomes; excluding women who miscarry more than one time from the sample and students. 2SLS estimates of the effect of the number of children on labor market outcomes. Each mark is a point estimate on the outcome indicated in the sub-figure header and the time period after expected birth indicated on the $x$-axis. The model is estimated on reduced samples, first excluding those who miscarry more than one time during the time window (open circles), second excluding students from the sample (open triangles). Separate estimates for the birth parities $p=1,2,3$ using miscarriages before the respective parity as the instruments. Included covariates are indicator variables for age at the expected birth measured in months and calendar year, continent of origin and industry in $t=-2$ 


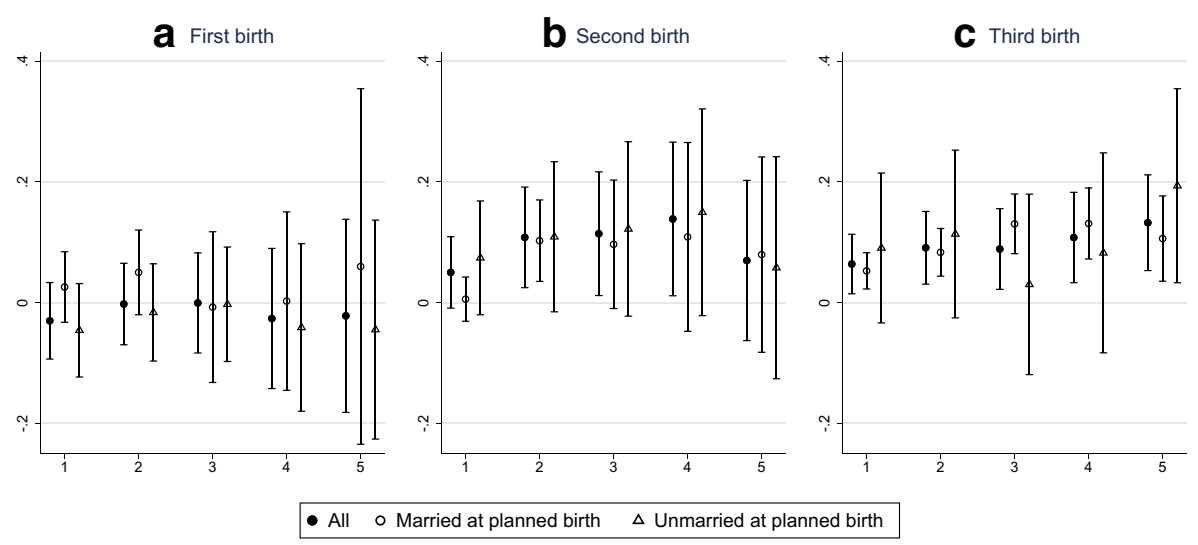

Fig. 12 IV estimates of the effect of the number of children on the probability of being married; by marital status in $t=-5$. 2SLS estimates of the effect of the number of children on marriage probabilities. Each mark is a point estimate in the time period after the expected birth indicated on the $x$-axis. Separate estimates for the birth parities $p=1,2,3$. Included covariates are indicator variables for age at the expected birth measured in months and calendar year, continent of origin and industry in $t=-2$

Open Access This article is licensed under a Creative Commons Attribution 4.0 International License, which permits use, sharing, adaptation, distribution and reproduction in any medium or format, as long as you give appropriate credit to the original author(s) and the source, provide a link to the Creative Commons licence, and indicate if changes were made. The images or other third party material in this article are included in the article's Creative Commons licence, unless indicated otherwise in a credit line to the material. If material is not included in the article's Creative Commons licence and your intended use is not permitted by statutory regulation or exceeds the permitted use, you will need to obtain permission directly from the copyright holder. To view a copy of this licence, visit http://creativecommonshorg/licenses/by/4. $0 /$.

\section{References}

Agüero JM, Marks MS (2008) Motherhood and female labor force participation: evidence from infertility shocks. Am Econ Rev 98(2):500-504

Agüero JM, Marks MS (2011) Motherhood and female labor supply in the developing world: evidence from infertility shocks. J Human Resour 46(4):800-826

Angelov N, Johansson P, Lindahl E (2016) Parenthood and the gender gap in pay. J Labor Econ 34(3):545579

Angrist JD, Evans WN (1998) Children and their parents' labor supply: evidence from exogenous variation in family size. Am Econ Rev 88(3):450-477

Ashcraft A, Lang K (2006) The consequences of teenage childbearing. Working Paper 12485, National Bureau of Economic Research

Ashcraft A, Fernàndez-Val I, Lang K (2013) The consequences of teenage childbearing: consistent estimates when abortion makes miscarriage non-random. Econ J 123(571):875-905

Bargain O, Gonzalez L, Keane C, Özcan B (2012) Female labor supply and divorce: new evidence from Ireland. Eur Econ Rev 56(8):1675-1691

Blau FD, Kahn LM (2013) Female labor supply: why is the United States falling behind? Am Econ Rev $103(3): 251-56$

Bonnet C, Garbinti B, Solaz A (2020) The flip side of marital specialization: the gendered effect of divorce on living standards and labor supply. J Popul Econ 1-59 
Bratti M, Cavalli L (2014) Delayed first birth and new mothers' labor market outcomes: evidence from biological fertility shocks. Eur J Popul 30(1):35-63

Bratti M, Fiore S, Mendola M (2020) The impact of family size and sibling structure on the Great MexicoUSA migration. J Popul Econ 33(2):483-529

Brier N (2008) Grief following miscarriage: a comprehensive review of the literature. J Women's Health 17(3):451-464

Broen AN, Moum T, Bødtker AS, Ekeberg I (2004) Psychological impact on women of miscarriage versus induced abortion: a 2-year follow-up study. Psychosom Med 66(2):265-271

Buckles KS, Munnich EL (2012) Birth spacing and sibling outcomes. J Human Resour 47(3):613-642

Cools S, Markussen S (2017) Strøm M. Children and careers: how family size affects parents' labor market outcomes in the long run. Demography 54(5):1773-1793

Cristia JP (2008) The effect of a first child on female labor supply: evidence from women seeking fertility services. J Human Resour 43(3):487-510

Cruces G, Galiani S (2007) Fertility and female labor supply in Latin America: new causal evidence. Labour Econ 14(3):565-573

Garcia-Enguidanos A, Calle M, Valero J, Luna S, Dominguez-Rojas V (2002) Risk factors in miscarriage: a review. Eur J Obstet Gynecol Reprod Biol 102(2):111-119

Hirvonen L (2009) The effect of children on earnings using exogenous variation in family size: Swedish evidence. Working Paper Series 2/2009, Swedish Institute for Social Research

Hotz VJ, Mullin CH, Sanders SG (1997) Bounding causal effects using data from a contaminated natural experiment: analysing the effects of teenage childbearing. Rev Econ Stud 64(4):575-603

Hotz VJ, McElroy SW, Sanders SG (2005) Teenage childbearing and its life cycle consequences: exploiting a natural experiment. The J Human Resour 40(3):683-715

Kleven H, Landais C, Posch J, Steinhauer A, Zweimüller J (2019a) Child penalties across countries: evidence and explanations. AEA Pap Proc 109:122-26

Kleven H, Landais C, Søgaard JE (2019b) Children and gender inequality: evidence from Denmark. Am Econ J Appl Econ 11(4):181-209

Kline J, Susser M, Stein Z (1989) Conception to birth: epidemiology of prenatal development / Jennie Kline, Zena Stein Mervyn Susser. Oxford University Press, New York

Lok IH, Yip ASK, Lee DTS, Sahota D, Chung TKH (2010) A 1-year longitudinal study of psychological morbidity after miscarriage. Fertil Steril 93(6):1966-1975

Lundborg P, Plug E, Rasmussen AW (2017) Can women have children and a career? IV evidence from IVF treatments. Am Econ Rev 107(6):1611-37

Magnus MC, Wilcox AJ, Morken NH, Weinberg CR, Håberg SE (2019) Role of maternal age and pregnancy history in risk of miscarriage: prospective register based study. BMJ 364

Miller A (2011) The effects of motherhood timing on career path. J Popul Econ 24(3):1071-1100

Miller AR (2009) Motherhood delay and the human capital of the next generation. Am Econ Rev 99(2):154-158

Olivetti C, Petrongolo B (2016) The evolution of gender gaps in industrialized countries. Ann Rev Econ $8(1): 405-434$

Rosenzweig MR, Wolpin KI (1980) Life-cycle labor supply and fertility: causal inferences from household models. J Polit Econ 88(2):328-348

Sieber SD (1974) Toward a theory of role accumulation. Am Sociol Rev 39(4):567-578

Publisher's note Springer Nature remains neutral with regard to jurisdictional claims in published maps and institutional affiliations. 